\title{
PARP1 Inhibition Augments UVB-Mediated Mitochondrial Changes-Implications for UV-Induced DNA Repair and Photocarcinogenesis
}

\author{
Csaba Hegedúis ${ }^{1}$, Gábor Boros ${ }^{2}$, Eszter Fidrus ${ }^{1}$, Gréta Nikoletta Kis ${ }^{3}$, Miklós Antal ${ }^{3}$, \\ Tamás Juhász ${ }^{3}{ }^{1}$, Eszter Anna Janka ${ }^{1}$, Laura Jankó ${ }^{4,5}$, György Paragh ${ }^{6}$, Gabriella Emri ${ }^{1}$,
} Péter Bai ${ }^{4,5,7, \dagger}$ and Éva Remenyik ${ }^{1, *,+}$

1 Department of Dermatology, Faculty of Medicine, University of Debrecen, 4032 Debrecen, Hungary; hegeduscsaba88@gmail.com (C.H.); fepont92@gmail.com (E.F.); janka.eszter.a@gmail.com (E.A.J.); gemri@med.unideb.hu (G.E.)

2 BioNTech RNA pharmaceuticals GmbH, BioNTech AG, 55131 Mainz, Germany; borosgabor27@gmail.com

3 Department of Anatomy, Histology and Embryology, Faculty of Medicine, University of Debrecen, 4032 Debrecen, Hungary; greta@anat.med.unideb.hu (G.N.K.); antal@anat.med.unideb.hu (M.A.); juhaszt@anat.med.unideb.hu (T.J.)

4 Department of Medical Chemistry, Faculty of Medicine, University of Debrecen, 4032 Debrecen, Hungary; janko.laura90@gmail.com (L.J.); baip@med.unideb.hu (P.B.)

5 MTA-DE Lendület Laboratory of Cellular Metabolism Research Group, University of Debrecen, H-4032 Debrecen, Hungary

6 Department of Dermatology and Department of Cell Stress Biology, Roswell Park Comprehensive Cancer Center, 665 Elm St, Buffalo, NY 14203 USA; gyorgy.paragh@roswellpark.org

7 Research Center for Molecular Medicine, Faculty of Medicine, University of Debrecen, 4032 Debrecen, Hungary

* Correspondence: remenyik@med.unideb.hu; Tel.: +36-52-412-345

+ Both authors are equally responsible for the paper.

Received: 26 November 2019; Accepted: 10 December 2019; Published: 18 December 2019

check for updates

\begin{abstract}
Keratinocytes provide the first line of defense of the human body against carcinogenic ultraviolet (UV) radiation. Acute and chronic UVB-mediated cellular responses were widely studied. However, little is known about the role of mitochondrial regulation in UVB-induced DNA damage. Here, we show that poly (ADP-ribose) polymerase 1 (PARP1) and ataxia-telangiectasia-mutated (ATM) kinase, two tumor suppressors, are important regulators in mitochondrial alterations induced by UVB. Our study demonstrates that PARP inhibition by ABT-888 upon UVB treatment exacerbated cyclobutane pyrimidine dimers (CPD) accumulation, cell cycle block and cell death and reduced cell proliferation in premalignant skin keratinocytes. Furthermore, in human keratinocytes UVB enhanced oxidative phosphorylation (OXPHOS) and autophagy which were further induced upon PARP inhibition. Immunoblot analysis showed that these cellular responses to PARP inhibition upon UVB irradiation strongly alter the phosphorylation level of ATM, adenosine monophosphate-activated kinase (AMPK), p53, protein kinase B (AKT), and mammalian target of rapamycin (mTOR) proteins. Furthermore, chemical inhibition of ATM led to significant reduction in AMPK, p53, AKT, and mTOR activation suggesting the central role of ATM in the UVB-mediated mitochondrial changes. Our results suggest a possible link between UVB-induced DNA damage and metabolic adaptations of mitochondria and reveal the OXPHOS-regulating role of autophagy which is dependent on key metabolic and DNA damage regulators downstream of PARP1 and ATM.
\end{abstract}

Keywords: UVB; PARP; mitochondria; metabolism; biogenesis; autophagy; carcinogenesis; DNA repair 


\section{Introduction}

Mitochondria regulate their shape, number, distribution, mass, content of mitochondrial DNA (mtDNA), and metabolic capacity in a process called mitochondrial biogenesis, which requires the orchestration of complex transcriptional control of both nuclear and mitochondrial genes [1,2]. The function of mitochondrial biogenesis is to provide quality control of mitochondria by regulating mitochondrial fission, fusion, and mitophagy [3,4] to maximize the energy utilization of mitochondria [5] to meet cellular and environmental demands. Imbalances or perturbations in these processes can lead to mitochondrial dysfunction $[3,6]$.

Accumulating evidence suggests that mitochondria also play a central role in skin physiology. Although, involvement of other organ systems predominates in classical mitochondrial disorders, several cutaneous diseases can be linked to mitochondrial dysfunctions [7]. Interestingly, mitochondria lack functional nucleotide excision repair (NER) pathway $[8,9]$ which is responsible for the removal of ultraviolet (UV)-induced DNA lesions including cyclobutane pyrimidine dimers (CPD). Accumulation of these DNA photoproducts in mtDNA leads to mutations and deletions resulting in mitochondrial alterations which have been associated with photoaging [10,11] and are present in melanoma [12], as well as in non-melanoma skin cancers $[13,14]$. The other types of mitochondrial alterations such as upregulated oxidative phosphorylation (OXPHOS), mitochondrial membrane hyperpolarization, and decreased mitophagy are frequently observed in patients with DNA repair deficiencies [15-18]. Even though, these DNA repair proteins are encoded by the nuclear genome, their absence lead to mitochondrial functional changes emphasizing the importance of nucleus-to-mitochondria (NM) signaling [19].

Growing evidence suggests that the key component of NM signaling is poly (ADP-ribose) polymerase 1 (PARP1) activation $[19,20]$. PARP1 is a multifunctional zinc-finger protein involved in the regulation of DNA repair, chromatin structure, cell cycle, calcium homeostasis, transcription regulation, cell death, immune response, and metabolism [21,22]. Through either direct interaction or via poly (ADP-ribose) (PAR) polymer formation PARP1 can modulate the activity of ataxia-telangiectasia mutated kinase (ATM) [23] and tumor suppressor protein 53 (p53) $[24,25]$ involved in DNA damage response. Enhanced PARP1 activity also induces ATP depletion [26], which implies the activation of AMPK-activated protein kinase (AMPK) $[27,28]$ that is responsible for the regulation of various cellular pathways including protein kinase B (AKT) and mammalian target of rapamycin (mTOR) [29-31]. This complex interplay between PARP1, ATM, AMKP, p53, AKT, and mTOR indicates that these DNA damage responders can fine-tune and modulate the interaction between DNA repair pathways with metabolism [32]. PARP1 and PARP2 also modulate mitochondrial activity through $\mathrm{NAD}^{+}$ depletion [33-35]. Pharmacological inhibition or deletion of PARP1 and PARP2 improves mitochondrial function and protects against mitochondrial [36,37], metabolic [34], and neurological diseases [38]. PARP inhibitors became valuable tools in treating cancer cells harboring DNA repair defect with the combination of either radio- or chemotherapy [39-41]. In addition to several orally-administered PARP inhibitors that are under active clinical development, recently ABT-888 (veliparib) has emerged as an effective drug in treating various solid tumors [42] partially via modulating mitochondrial activity $[43,44]$.

Although UV radiation has been shown to trigger morphological $[45,46]$ and functional changes of mitochondria [47-49], published data led to contradictory results most likely due to the diversity of applied UV spectrum, UV dose, and cell type. Studies using UVC irradiation revealed that UVC induced mitochondrial hyperfusion and resulted in enhanced ATP synthesis via oxidative phosphorylation (OXPHOS) [50]. Other authors demonstrated that UVC irradiation caused a significant increase in mitochondrial content, oxygen consumption, and fatty acid oxidation [28]. Nevertheless, the functional consequences of mitochondrial alterations after UVB-induced DNA damage and the molecular pathways leading to mitochondrial changes remain to be elucidated. 
In this study, we defined the central role of PARP1 and the linked molecular pathways in mediating UVB-induced DNA damage response and mitochondrial changes in a clinically relevant human keratinocyte cell line.

\section{Results}

\subsection{PARP Inhibition Impairs CPD Repair, Augments UVB-Induced Cell Cycle Block, Apoptosis and Reduces} Keratinocyte Proliferation

To explore the effect of UVB on PARP activation, firstly, we investigated poly (ADP-ribose) polymer (PAR) formation in a time-dependent manner in human immortalized keratinocytes exposed to $\mathrm{mid}\left(20 \mathrm{~mJ} / \mathrm{cm}^{2}\right)$ or high $\left(40 \mathrm{~mJ} / \mathrm{cm}^{2}\right)$ dose of UVB (Figure 1A). In HaCaT cells, poly (ADP-ribosyl) ation (PARylation) signal was initially observed at and over $95 \mathrm{kDa}$ at $5 \mathrm{~min}$ after UVB exposure and the extent of PARP activation was dose-dependent with higher PARP activation after $40 \mathrm{~mJ} / \mathrm{cm}^{2} \mathrm{UVB}$ exposure. The signal was lost when cells were treated with ABT-888, a pan-PARP inhibitor (for uncut PAR western see Supplementary Figure S2). PARP1 is considered to contribute $85-90 \%$ to total PARP activity, the rest is largely the activity of PARP2 [51-53]. Moreover, the size of the PARylated band suggests PARP1 (auto) PARylation indicating the involvement of PARP1 in UVB-induced damage. Since PARP1 is involved in regulation of various DNA repair pathways, we wanted to assess how PARP inhibition (PARPi) regulates the removal of cyclobutane pyrimidine dimers (CPDs) introduced by UVB (Figure 1B). A slow decline of CPDs after UVB exposure was observed, reflective of nucleotide excision repair (NER) activity. In contrast, the relative amount of CPDs in PARP-inhibited cells remained elevated even after $24 \mathrm{~h}$ compared to the UVB-irradiated cells suggesting impaired efficiency of NER, similarly as described by King et al. [54]. Since unrepaired photolesions can initiate cell cycle block to prevent cells with DNA damage from entering mitosis, we performed cell cycle analysis (Figure 1C,D). A higher proportion of PARP-inhibited cells after $20 \mathrm{~mJ} / \mathrm{cm}^{2} \mathrm{UVB}$ accumulated in $\mathrm{G}_{2} / \mathrm{M}$ phase of cell cycle characteristic of enhanced DNA damage [21]. ABT-888 treatment sensitized cells to apoptosis after UVB as reflected by decreased cell viability $24 \mathrm{~h}$ post-UVB compared to controls (Figure 1E). Gene silencing of PARP1 showed similar changes regarding cell viability as PARP inhibition. Furthermore, long-term keratinocyte survival using May-Grünwald-Giemsa staining in clonogenic assay showed that ABT-888 treatment led to a marked decrease in the number of keratinocyte clones after UVB-irradiation (Figure 2A,B). To find out whether PARPi-induced retention of CPDs induce higher mutation rate, we performed hypoxanthine-guanine phosphoribosyltransferase (HPRT) mutation assay (Figure 2C,D). We could not adjust the method for HaCaT keratinocytes as these cells were extremely tolerant to the 6-thioguanine selection medium. Therefore, we used Chinese hamster ovary (CHO) cells which is a widely used cell line for HPRT mutation assay [55-57] and also show high level of p53 protein level due to p53 mutation [58,59] as HaCaT cells do [60]. In this case, we used lower UVB doses to allow the accumulation of mutations compared to higher UVB which potentially triggers apoptosis. Although, both 10 and $20 \mathrm{~mJ}$ UVB resulted in increased number of HPRT-mutated cells, interestingly PARP inhibition caused a marked reduction in the number of mutated cell colonies suggesting that PARPi initiate apoptosis of cells with high CPD content instead of allowing the accumulation of gene mutations. Interestingly, some DNA damage markers, including cell viability, CPD and colony formation, cell cycle progression showed no significant difference between the vehicle and ABT-888 treated groups after $40 \mathrm{~mJ} / \mathrm{cm}^{2}$. This phenomenon can be due to the fact that $40 \mathrm{~mJ} / \mathrm{cm}^{2} \mathrm{UVB}$ dose in our experiments represents such high DNA damage that cannot be augmented by PARP inhibition. However, PARP1 knockdown cells displayed significantly lower cell viability compared to control siRNA-transfected cells even after $40 \mathrm{~mJ} / \mathrm{cm}^{2}$ UVB irradiation. 
A

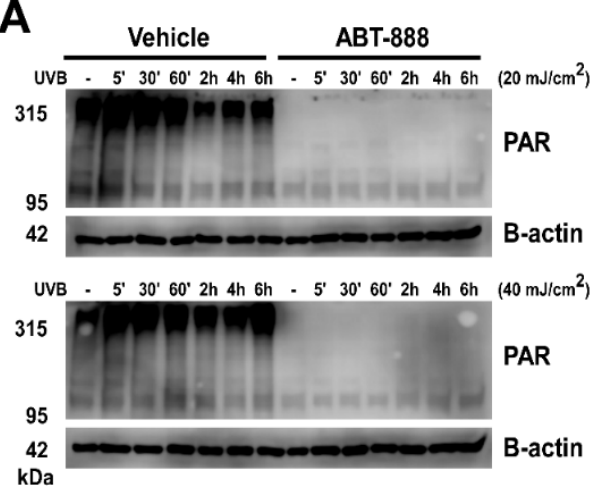

$\mathrm{C}_{4}$

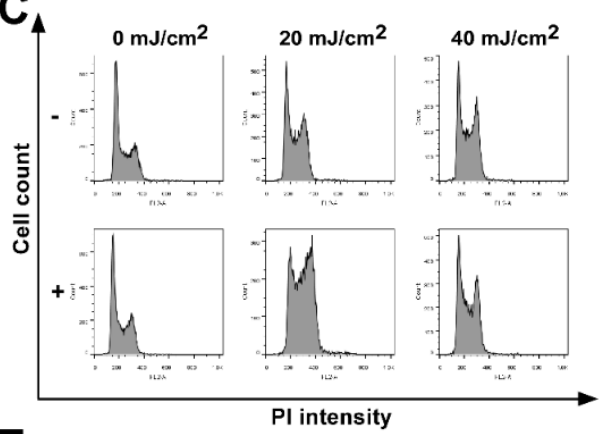

E

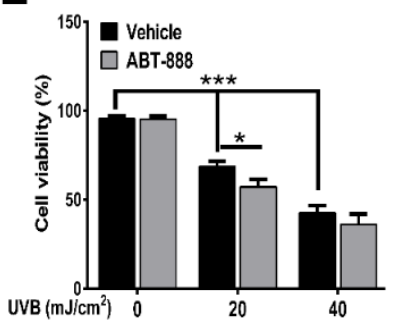

B
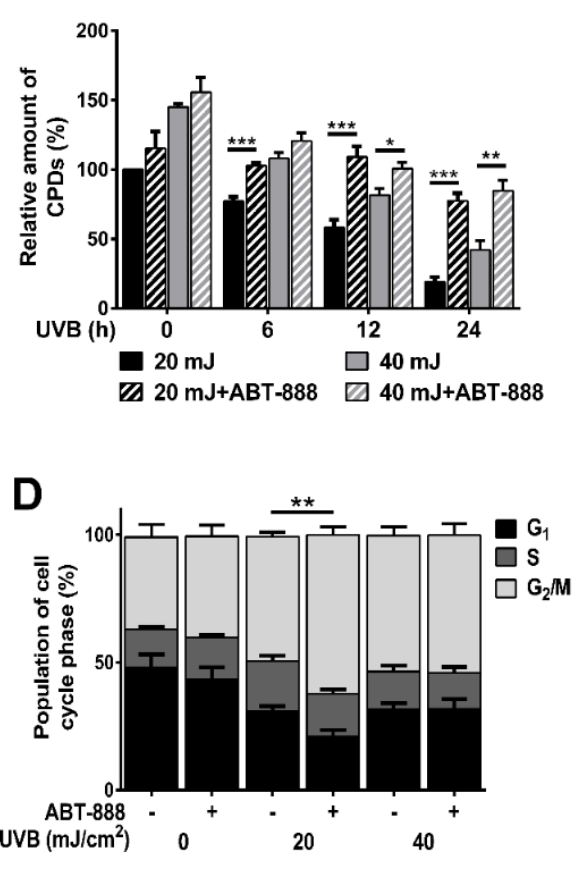
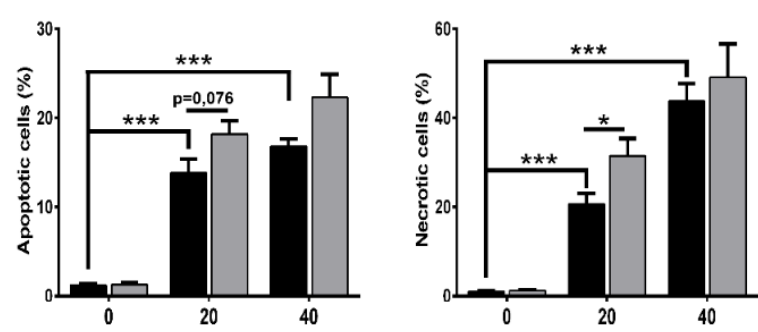

F

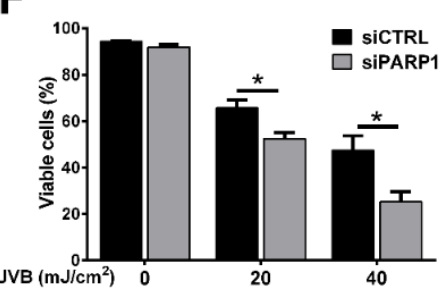

Figure 1. Poly (ADP-ribose) polymerase (PARP) inhibition impairs cyclobutane pyrimidine dimer (CPD) repair, augments ultraviolet B (UVB)-induced cell cycle block and apoptosis. (A) Time-course of PARP activity (PAR) after 20 and $40 \mathrm{~mJ} / \mathrm{cm}^{2}$ UVB exposure and $25 \mu \mathrm{M}$ ABT-888 were analyzed by Western blot $(n=3)$. (B) Cells were exposed to a single dose of 20 or $40 \mathrm{~mJ} / \mathrm{cm}^{2} \mathrm{UVB}$ and collected at various time points for DNA extraction. CPD formation was determined by ELISA $(n=4)$. (C,D) Cell cycle progression was evaluated by propidium iodide staining after $24 \mathrm{~h}$. DNA content was analyzed in FL2-A $(n=4)$. (E) Cell viability, apoptosis, and necrosis was assessed by dual labelling with Annexin V-Alexa 488 and propidium iodide $24 \mathrm{~h}$ post-UVB. Double negative cells are considered as viable $(n=5)$. (F) Cell viability was measured similarly as in Figure 1E after PARP1 knockdown $(n=3) .-/+$ represent vehicle (-) or ABT-888 (+) treatment *; ${ }^{* *}$ and ${ }^{* * *}$ indicate statistically significant difference at $p<0.05$ and $p<0.01, p<0.001$, respectively. Error bars represent SEM. 

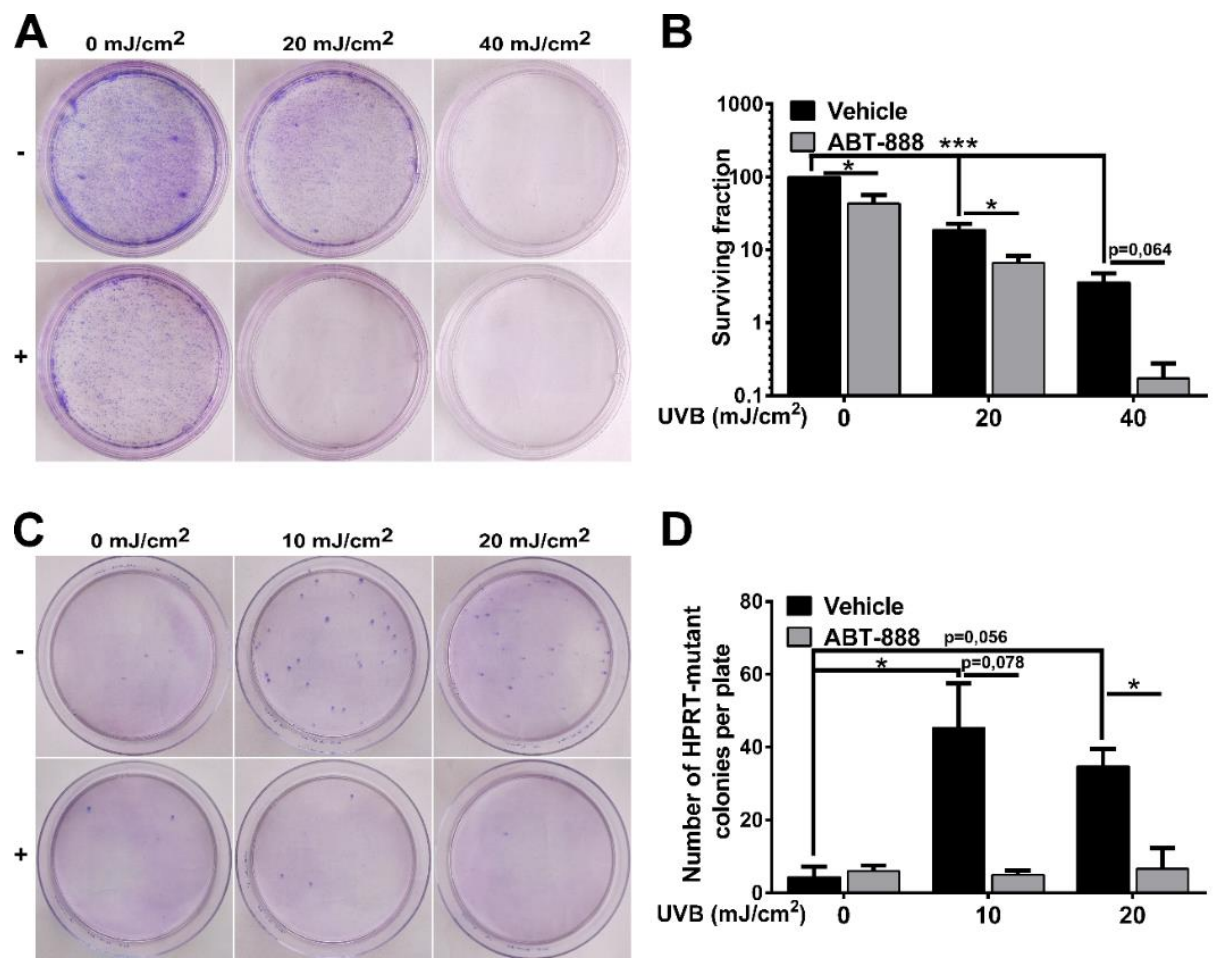

Figure 2. Poly (ADP-ribose) polymerase (PARP) inhibition decreases clone formation and ultraviolet $B$ (UVB)-induced mutation rate. (A,B) Colony formation assay of HaCaT cells after 10 days post-UVB exposure was assessed by clonogenic assay $(n=4)$. (C,D) HPRT mutation assay was carried out on $\mathrm{CHO}$ cells. Preselected hypoxanthine-guanine phosphoribosyltransferase (HPRT) mutant cells were cultured for 10 days post-UVB $(n=3)$. $-/+$ represent vehicle $(-)$ or ABT-888 $(+)$ treatment ${ }^{*}$ and ${ }^{* * *}$ indicate statistically significant difference at $p<0.05$ and $p<0.001$, respectively. Error bars represent SEM.

\subsection{PARP Inhibition Enhances UVB-Mediated Mitochondrial Biogenesis}

Mitochondrial biogenesis, by promoting the growth, formation, and assembly of newly synthesized mitochondria, has recently been linked to cancer development [61], apoptosis [62-64], and DNA damage $[18,28,65]$. Accumulating evidence suggest that DNA damage can initiate mitochondrial biogenesis which is accompanied by elevation in mitochondrial number, area, and mass $[18,28,65,66]$. Transmission electron microscopic images revealed that UVB-treated cells contain more and longer cristae than non-irradiated cells (Figure 3A). This morphological alteration became more pronounced after PARP inhibition. Similarly, UVB treatment increased both mitochondria number and total mitochondrial area (Figure 3B,C). ABT-888 treatment resulted in further increase in these parameters suggesting that PARP inhibition may boost UVB-mediated mitochondrial response. Since mitochondrial content changes with the balance between mitochondrial biogenesis and turnover, we quantified mitochondrially encoded cytochrome C oxidase I (MTCO1)/succinate dehydrogenase complex, subunit A (SDHA) ratio that is a marker of mitochondrial biogenesis. This experiment demonstrated that the mitochondrially-encoded MTCO1 show strong induction after UVB irradiation and become even more expressed after PARPi, while the expression of the nuclearly-encoded SDHA protein is unaltered (Figure 3D,E). The higher mitochondrial mass after both UVB and PARPi (Figure 3F) and the enhanced expression of the master regulators of mitochondrial biogenesis including mitochondrial transcription factor A (TFAM), nuclear respiratory factor 2 (NRF2), and estrogen-related receptor alpha (ERRA) (Figure $3 \mathrm{G}$ ) also suggest that PARPi augments the UVB-triggered mitochondrial biogenesis. 
A
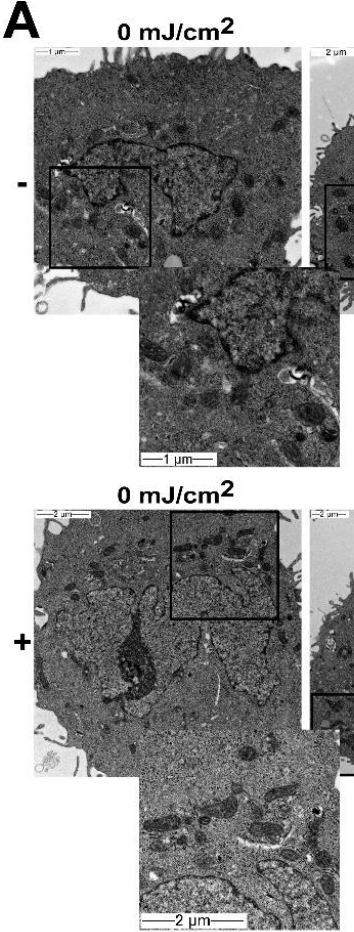

D

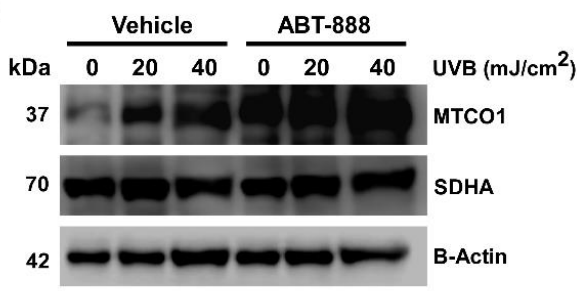

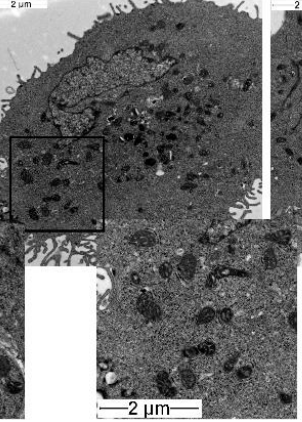

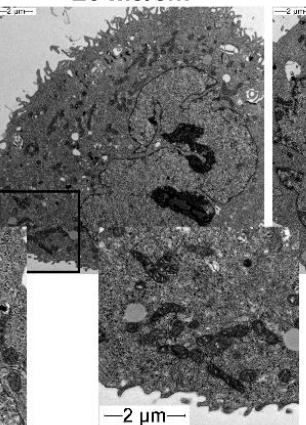

$40 \mathrm{~mJ} / \mathrm{cm}^{2}$

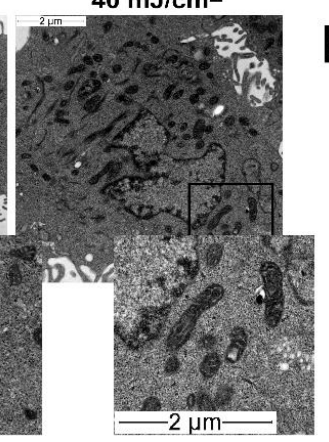

$40 \mathrm{~mJ} / \mathrm{cm}^{2}$

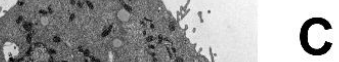

C
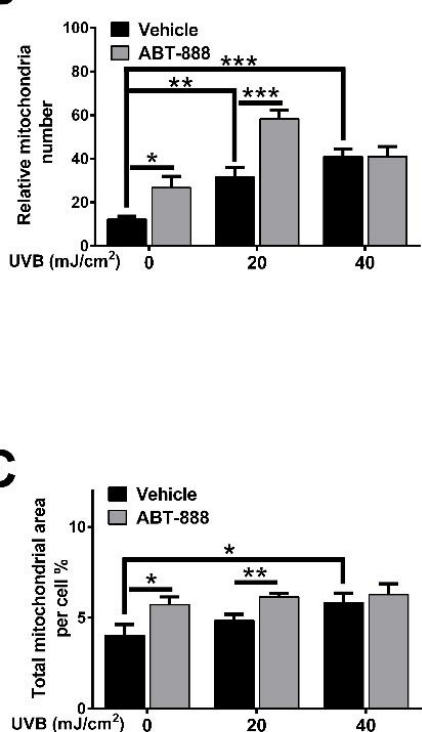

F

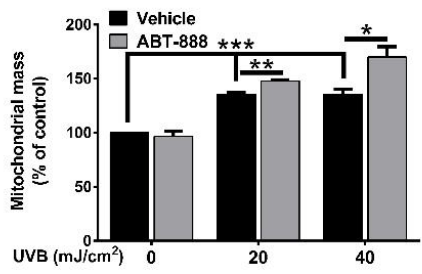

\section{G}

E

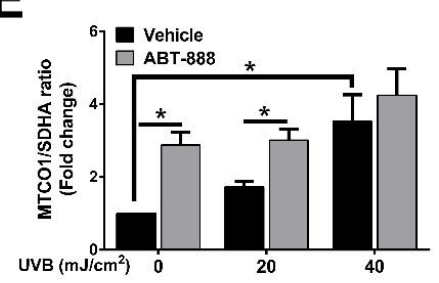

Figure 3. Poly (ADP-ribose) polymerase (PARP) inhibition enhances ultraviolet B (UVB)-mediated mitochondrial biogenesis. (A) Effect of UVB irradiation and PARP inhibition on mitochondrial ultrastructure visualized by transmission electron microscopy (TEM) $24 \mathrm{~h}$ after UVB exposure. Enlarged pictures are displayed at the right bottom corner. Scale bar is presented on the lower panels. (B) Mitochondrial number and (C) area were calculated from TEM images (minimum 7 cells were analyzed). (D,E) Mitochondrial biogenesis was quantified by the ratio of the mitochondrially encoded cytochrome C oxidase I (MTCO1) and succinate dehydrogenase complex, subunit A (SDHA) expression $24 \mathrm{~h}$ post UVB $(n=3)$. (F) Mitochondrial mass was determined by Mitotracker Green labeling $24 \mathrm{~h}$ after UVB irradiation $(n=3)$. (G) mRNA levels of master regulators of mitochondrial biogenesis were quantified by real-time PCR $24 \mathrm{~h}$ post-UVB $(n=\min .3) .-/+$ represent vehicle $(-)$ or ABT-888 (+) treatment. *; ** and ${ }^{* * *}$ indicate statistically significant difference at $p<0.05$ and $p<0.01, p<0.001$, respectively. Error bars represent SEM. 


\subsection{PARP Inhibition Augments UVB-Mediated Mitochondrial Fusion}

To identify if UVB and PARPi also alters mitochondrial dynamics, we evaluated mitochondrial morphology using confocal microscopy. Non-irradiated cells mainly contained fragmented mitochondria which normally represents low metabolic activity. After $40 \mathrm{~mJ} / \mathrm{cm}^{2} \mathrm{UVB}$, a statistically significant reduction in the frequency of fragmented mitochondria and an elevation in tubular mitochondria was detected compared to the non-irradiated control. The frequency of intermediate mitochondria was increased after PARPi at $0 \mathrm{~mJ}$ UVB compared to the vehicle control, and we also observed decreased fragmented mitochondrial frequency and higher percentage of tubular mitochondria after $20 \mathrm{~mJ} / \mathrm{cm}^{2}$ + ABT- 888 treatment compared to the $20 \mathrm{~mJ} / \mathrm{cm}^{2} \mathrm{UVB}$ exposed cells (Figure 4A). The dose-dependent effect of UVB in the branching aspect of mitochondria (Figure 4C) as defined by form factor ((Perimeter ${ }^{2} /(4 \pi \times$ area $\left.)\right)$ was also observed suggesting enhanced mitochondrial fusion after UVB and PARP inhibition. Finally, to confirm that the observed mitochondrial fusion are regulated by the dynamin-related proteins, we checked the expression of mitofusin-1 (Mfn1), mitofusin-2 (Mfn2), and optic atrophy 1 (OPA1) (Figure 4D,E). Similarly to mitochondrial morphological alterations, we detected enhanced protein expression of Mfn1, Mfn2, and OPA1 which support mitochondrial fusion at the outer and inner mitochondrial membrane. These results clearly indicate that besides enhancing mitochondrial biogenesis, UVB also triggers mitochondrial fusion and increases the complexity of mitochondrial network which is more prominent after PARP inhibition.

\subsection{PARP Inhibition and UVB Induces Bulk Autophagy but Not Mitophagy}

Several DNA-damaging agents were shown to initiate autophagy $[67,68]$ and mitophagy [69] to remove damaged macromolecules or organelles including mitochondria, which prompted us to explore if UVB and PARPi-induced mitochondrial biogenesis and morphological changes of mitochondria affects autophagy or mitophagy. We used dual labelling of Mitotracker CMxROS to stain mitochondria and microtubule-associated proteins 1A/1B light chain 3B (LC3A/B) antibody to detect autophagosomes. Our results show the accumulation of LC3-positive cells after UVB exposure. PARP inhibition augmented autophagy not only in UVB-exposed cells, but also under non-irradiated conditions (Figure 5A,B). LC3B western blotting (Figure 5C) also confirmed these results indicating the autophagy inducer role of ABT-888. PARP1 knockdown also showed similar results but with much more pronounced autophagy induction after UVB (Figure 5E). Interestingly, the role of PARP1 in the regulation of autophagy is controversial. Both autophagy inductor [70-72] and inhibitor [73-75] role of PARP1 has been described suggesting that the autophagy-modulatory effect of PARylation might show DNA damage and cell type specificity. Even though, we detected an increased number of LC3 puncta, this type of macroautophagy cannot be considered as mitophagy since autophagic puncta show very mild colocalization with mitochondria (Figure 5D). Furthermore, a dose-dependent mitochondrial elongation was observed after UVB and PARP inhibition in Figure 4A,B indicating mitochondrial fusion. Since fused mitochondria are protected from mitophagy [76], and mitophagy-coupled elimination of mitochondria is usually preceded by fission [69] and decline in mitochondrial function [77], the here experienced induction in autophagy is considered as general autophagy and suggest that mitochondrial morphological rearrangements induced by UVB and PARPi may interfere with the initiation of mitophagy. 

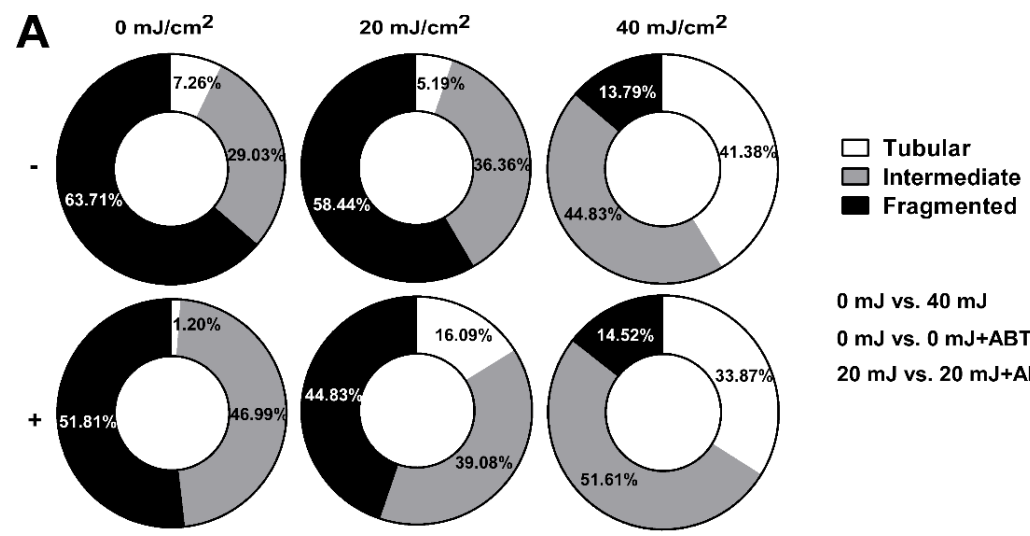

B

$0 \mathrm{~mJ} / \mathrm{cm}^{2}$

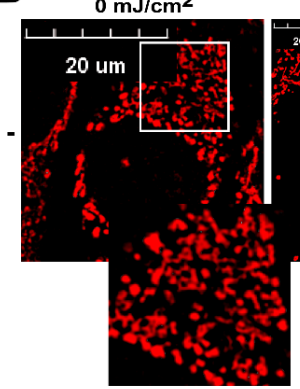

$20 \mathrm{~mJ} / \mathrm{cm}^{2}$

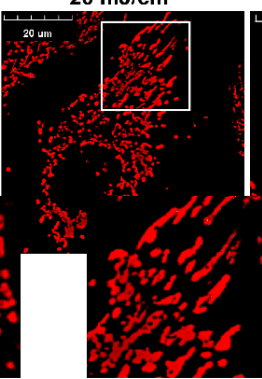

$40 \mathrm{~mJ} / \mathrm{cm}^{2}$

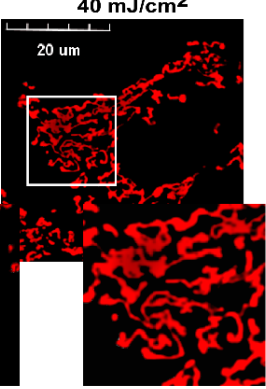

C

$0 \mathrm{~mJ}$ vs. $40 \mathrm{~mJ} \quad \mathrm{p}<0.001$

$0 \mathrm{~mJ}$ vs. $0 \mathrm{~mJ}+\mathrm{ABT}-888 \mathrm{p}=0.008$

$20 \mathrm{~mJ}$ vs. $20 \mathrm{~mJ}+\mathrm{AB}-888 \mathrm{p}=0.002$
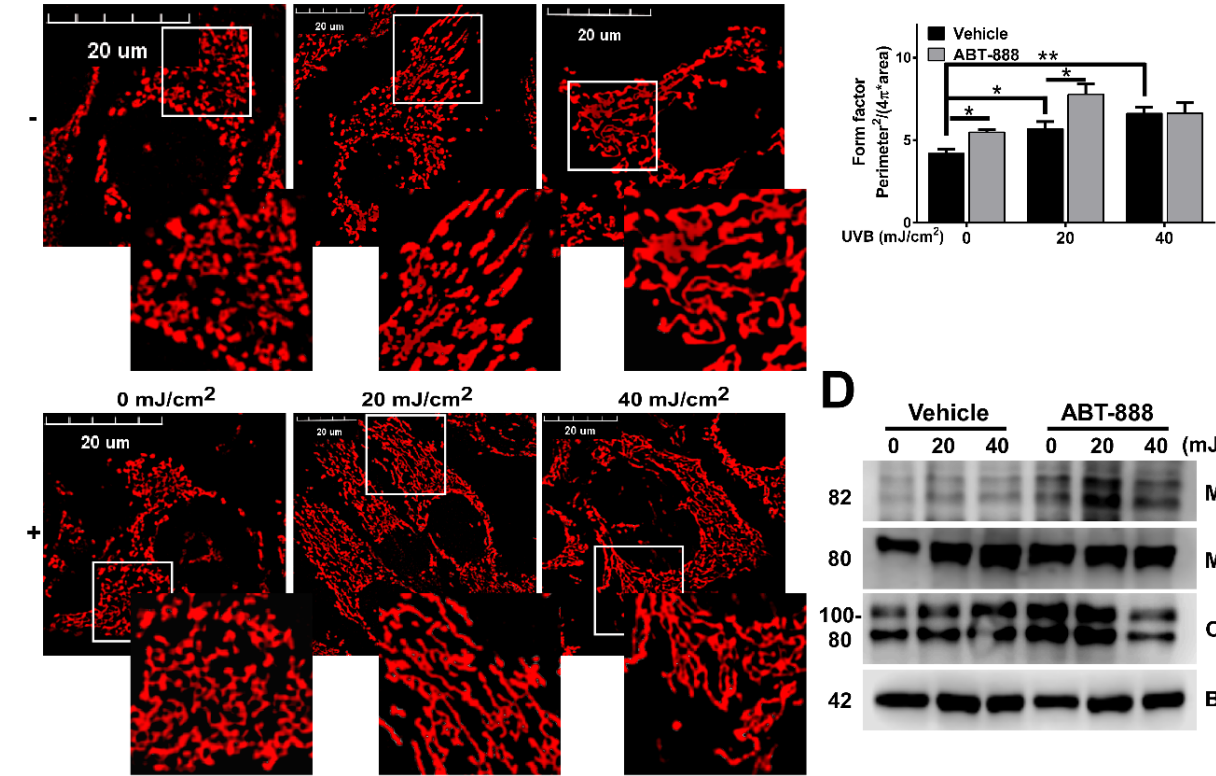

$20 \mathrm{~mJ} / \mathrm{cm}^{2}$

$40 \mathrm{~mJ} / \mathrm{cm}^{2}$

\section{D}

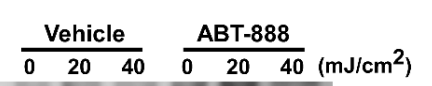

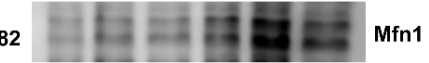

${ }_{80} 0$ Mfn2

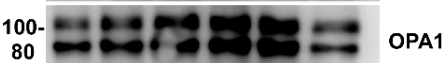

42
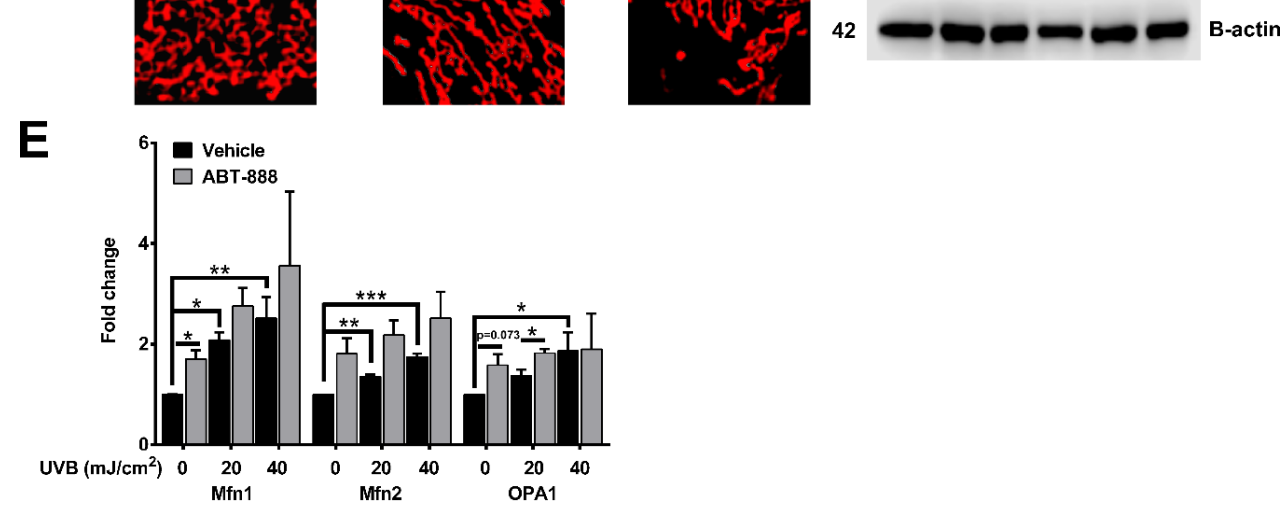

Figure 4. Poly (ADP-ribose) polymerase (PARP) inhibition augments ultraviolet B (UVB)-mediated mitochondrial fusion. (A) Effect of UVB irradiation and PARP inhibition on mitochondrial morphological subtypes (tubular, intermediate, and fragmented) are quantified based on confocal microscopic images $24 \mathrm{~h}$ post-UVB (minimum 29 cells). (B) Mitochondrial morphology visualized by confocal microscopy with Mitotracker Red CMXRos dye $(n=3)$. Enlarged pictures are displayed at the right bottom corner. Scale bar is presented on the images. (C) The branching aspect of mitochondria was derived from confocal microscopic images and was represented as a form factor $(n=3)$. (D) Protein expression of mitofusin-1 (Mfn1), mitofusin-2 (Mfn2), and optic atrophy 1 (OPA1) was visualized by Western blot. (E) Expression of mitochondrial fusion proteins were analyzed by Western blot $24 \mathrm{~h}$ post-UVB $(n=$ min. 3). $-/+$ represent vehicle (-) or ABT-888 (+) treatment. *; $* *$ and ${ }^{* * *}$ indicate statistically significant difference at $p<0.05$ and $p<0.01, p<0.001$, respectively. Error bars represent SEM. 
A
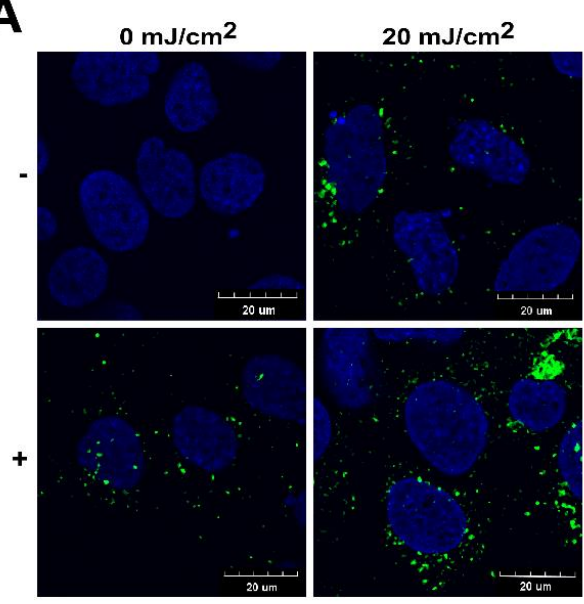

$20 \mathrm{~mJ} / \mathrm{cm}^{2}$
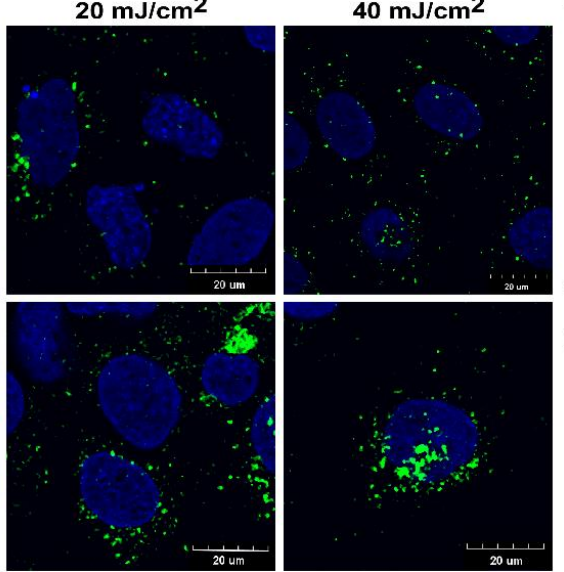

B
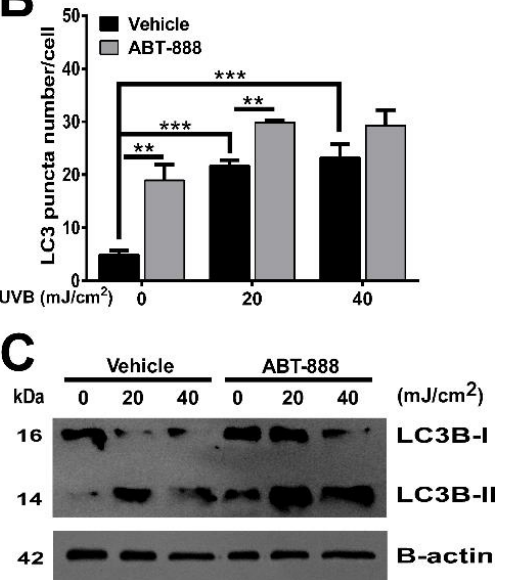

D
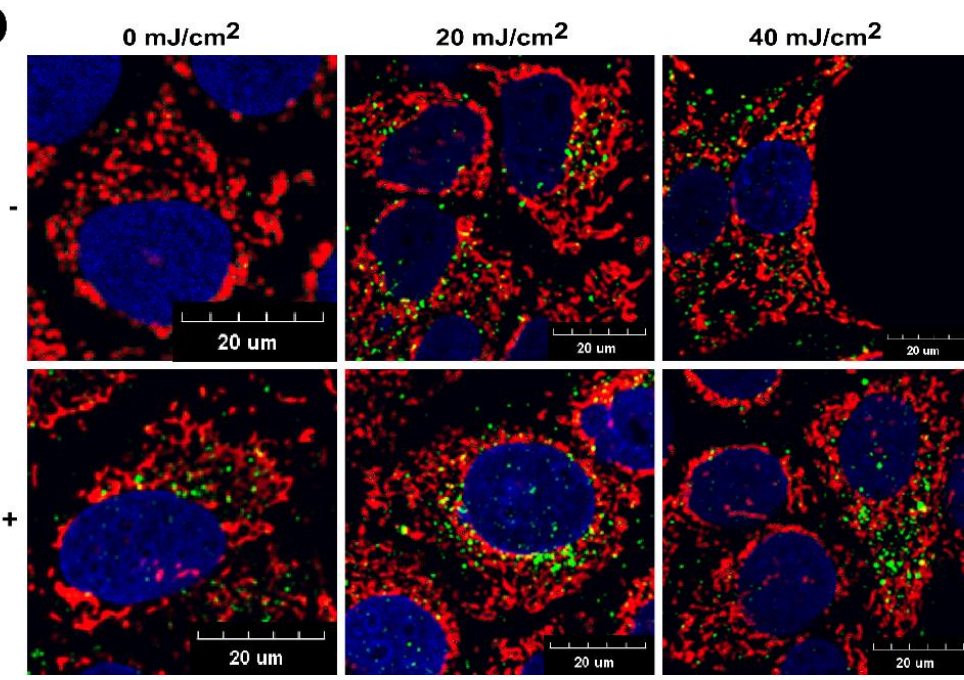

BLUE

DAPI

Nucleus

GREEN

LC3A/B

Autophagosomes

RED

Mitotracker CMXRos

Mitochondria

E

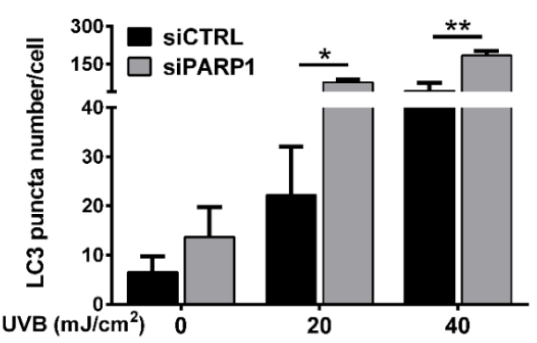

Figure 5. Poly (ADP-ribose) polymerase (PARP) inhibition and ultraviolet B (UVB) induces bulk autophagy but not mitophagy. (A) Expression of microtubule-associated proteins 1A/1B light chain 3B (LC3A/B) protein marker of autophagy by confocal microcopy $(n=3)$. Scale bar is presented on the figure. (B) Quantification of LC3A/B puncta in cells derived from confocal images in Figure 5A $(n=3)$. (C) LC3A/B proteins were quantified by Western blotting. Brightness and contrast were adjusted. Protein of interest were normalized to the loading control B-actin. (D) Dual staining of LC3-puncta and mitochondria by confocal microscopy $(n=3)$. (E) Quantification of LC3A/B puncta in PARP1 siRNA and control siRNA-transfected cells derived from confocal images $(n=4)-/+$ represent vehicle $(-)$ or ABT-888 (+) treatment *;* and ${ }^{* * *}$ indicate statistically significant difference at $p<0.05, p<0.01$ and $p<0.001$, respectively. Error bars represent SEM. 


\subsection{PARP Inhibition Boosts UVB-Mediated Mitochondrial Bioenergetic Changes}

Alterations in the mitochondrial network is strictly controlled by intra- or extracellular signals connecting mitochondrial biogenesis and fusion with energy perturbations. To test whether increased mitochondrial biogenesis and fusion after UVB and PARP inhibition supports mitochondrial activity, we evaluated mitochondrial parameters. Our results show that UVB exposure increased mitochondrial membrane potential (Figure 6A) and total ATP level (Figure 6B). PARPi boosted the UVB-induced mitochondrial membrane hyperpolarization and it also raised ATP level compared to UVB-irradiated samples. Mitochondrial membrane potential and ATP levels change independently, and hyperpolarization of mitochondrial membrane potential does not necessarily correlate with ATP production but it may stem from decreased $\mathrm{F}_{0} \mathrm{~F}_{1}$ ATP synthase activity and concomitant lower ATP production. Furthermore, increased ATP level may result either from enhanced glycolysis, increased respiration via electron flow from complex I-V, or decreased energy expenditure. In order to clarify the reasons of the elevation in ATP levels, we complemented our data with quantitative analysis of metabolic flux by XF96 oximeter and monitored extracellular acidification rate (ECAR) indicating glycolysis and oxygen consumption (OCR) representing oxidative phosphorylation with sequential addition of oligomycin and antimycin. Although basal ECAR (Figure 6C) is statistically unchanged after UVB exposure, PARP inhibition enhanced the rate of glycolysis after $20 \mathrm{~mJ} / \mathrm{cm}^{2} \mathrm{UVB}$ dose and at non-irradiated conditions. In contrast, UVB dose-dependently increased oxygen consumption and ABT-888 treatment significantly augmented OXPHOS compared to 0 or $20 \mathrm{~mJ} / \mathrm{cm}^{2} \mathrm{UVB}$ (Figure $6 \mathrm{C}$ ). Citrate synthase (CS) activity, the initial enzyme in the tricarboxylic acid (TCA) cycle catalyzing the formation of citrate from oxalacetate and acetyl-CoA, showed significant elevation after UVB radiation, which was augmented by PARP inhibition (Figure 6C). This suggest that not only the distal part of respiratory chain is altered by UVB and PARPi, but also increased terminal oxidation is preceded by elevation in TCA activity as well. To exclude the possibility of the off-target effects of ABT-888, we confirmed the mitochondrial changes by PARP1 silencing. We detected increased mitochondrial mass reflecting mitochondrial biogenesis after UVB in control siRNA-transfected keratinocytes that was elevated by PARP1 knockdown (Figure 6D). Mitotracker Red CMXRos incorporation into mitochondria reflecting mitochondrial membrane potential also showed similar changes similarly after vehicle and ABT-888 treatment (Figure 6E). Although, we could not detect difference in basal ECAR between the control and PARP siRNA-transfected cells, CS activity and OXPHOS showed significant changes (Figure 6F) confirming the pivotal role of PARP1 in the UVB-induced mitochondrial changes. In summary, we can conclude that elevation in cellular ATP level after UVB is due to enhanced energy production and cells increase their energy reserves through both glycolysis, TCA cycle, and OXPHOS after PARP inhibition. 
A

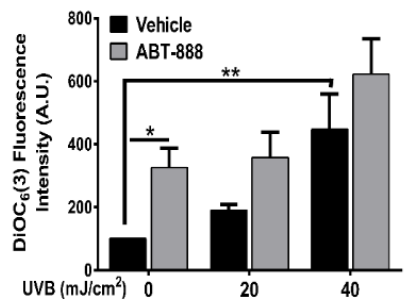

B

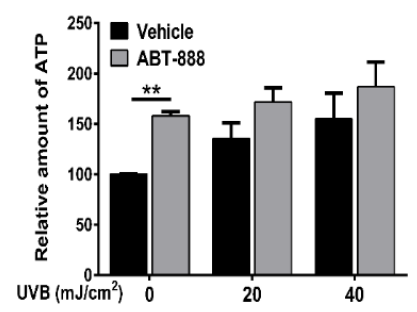

C
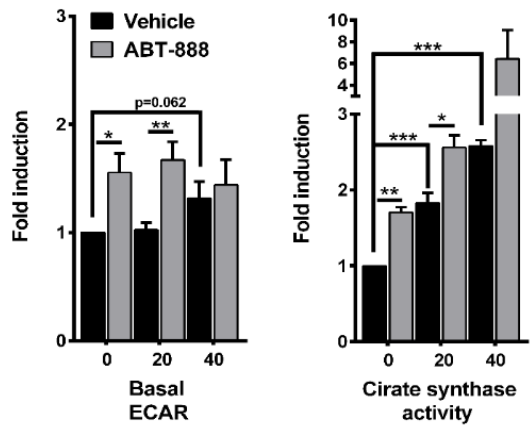

E
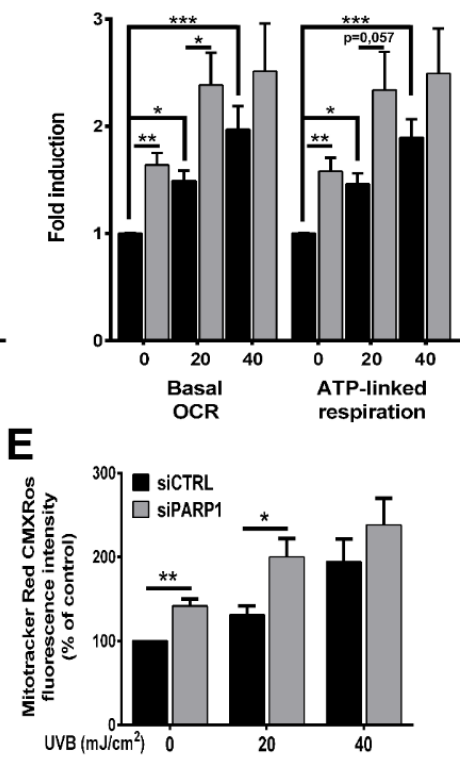

F

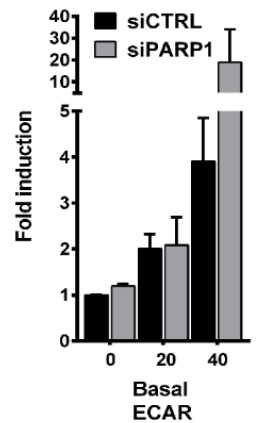

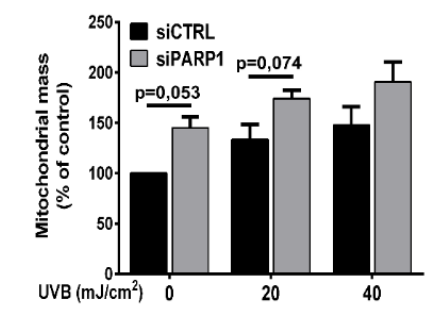

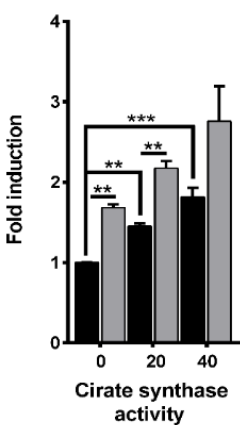

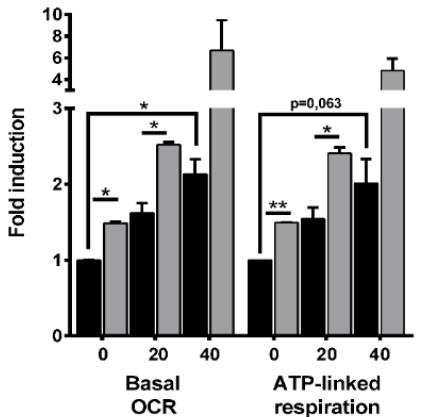

Figure 6. PARP inhibition boosts UVB-mediated mitochondrial bioenergetic changes. (A) For determination of mitochondrial membrane potential cells were stained with 3,3'-dihexyloxacarbocyanine iodide $\left(\mathrm{DIOC}_{6}(3)\right) 24 \mathrm{~h}$ post-UVB and measured by flow cytometry in FL1 channel $(n=4)$. (B) Total cellular ATP level was quantified by colorimetric assay $(n=3)$. (C) Basal extracellular acidification rate (ECAR) represents glycolysis after $24 \mathrm{~h}$ post-UVB. XF medium was supplemented with $10 \mathrm{mM}$ glucose $(n=6)$. After four oxygen consumption rate (OCR) measurement oligomycin and antimycin was used to determine mitochondria-linked ATP production and basal OCR, respectively $(n=6)$. Citrate synthase activity, the initial enzyme of the tricarboxylic acid (TCA) cycle was measured by citrate synthase kit $(n=3)$. (D) Mitochondrial mass determined similarly as in Figure 3F $(n=4)$. (E) Mitotracker Red CMXRos mean fluorescence intensity was measured by flow cytometry $(n=4)$. (F) Metabolic parameters including glycolysis, citrate synthase activity, and oxidative phosphorylation (OPXHOS) was detected similarly as in Figure $6 \mathrm{C}$ ( $n=2$ for ECAR and OCR, $n=3$ for citrate synthase (CS) activity). ${ }^{*} p<0.05,{ }^{* *} p<0.01$, *** $p<0.001$. 


\subsection{PARP Inhibition Restores $N A D^{+}$Level and SIRTUIN Expression}

$\mathrm{NAD}^{+}$and NADH plays a central role in redox homeostasis and cellular metabolism including glycolysis via glyceraldehyde-3-phosphate dehydrogenase (GAPDH) activity [78] and OXPHOS by regulating the transfer of electrons to complex I [79]. UVB irradiation caused a slight but significant decrease in $\mathrm{NAD}^{+}$level after both 20 and $40 \mathrm{~mJ} / \mathrm{cm}^{2} \mathrm{UVB}$ (Figure 7A). ABT-888 treatment efficiently restored intracellular $\mathrm{NAD}^{+}$content suggesting the role of PARP1 in UVB-mediated NAD ${ }^{+}$ depletion. It has been known that a decrease in $\mathrm{NAD}^{+}$by enhanced PARP activation inhibits another $\mathrm{NAD}^{+}$-consuming enzyme family, the class III histone deacetylase Sirtuins $[33,34,36-38,80]$ which regulate diverse cellular processes [81] including mitochondrial metabolism and have intricate relationships with PARPs [82,83]. To test whether UVB modulate Sirtuin expression and PARPi can restore their expression after UVB similarly as NAD level changes, we chose the $40 \mathrm{~mJ} / \mathrm{cm}^{2} \mathrm{UVB}$ dose which caused a more significant increase in $\mathrm{NAD}^{+}$level after ABT-888 treatment compared to UVB-irradiated cells. We detected slight mRNA downregulation in SIRT1, SIRT2, SIRT3, SIRT4, SIRT5, and SIRT7 after $40 \mathrm{~mJ} / \mathrm{cm}^{2}$ UVB dose (Figure 7B) and PARP inhibition increased the gene expression of all Sirtuins suggesting that intracellular $\mathrm{NAD}^{+}$availability after UVB and PARPi may regulate SIRTs expression. Although, the role of Sirtuins in the UVB-mediated cellular response and skin physiology is poorly characterized [84-88], here we revealed the Sirtuin expression-modulatory effect of NAD ${ }^{+}$ after UVB and PARP inhibition. To explore the potential role of $\mathrm{NAD}^{+}$and Sirtuins in supporting glycolysis or oxidative phosphorylation further experiments are needed.
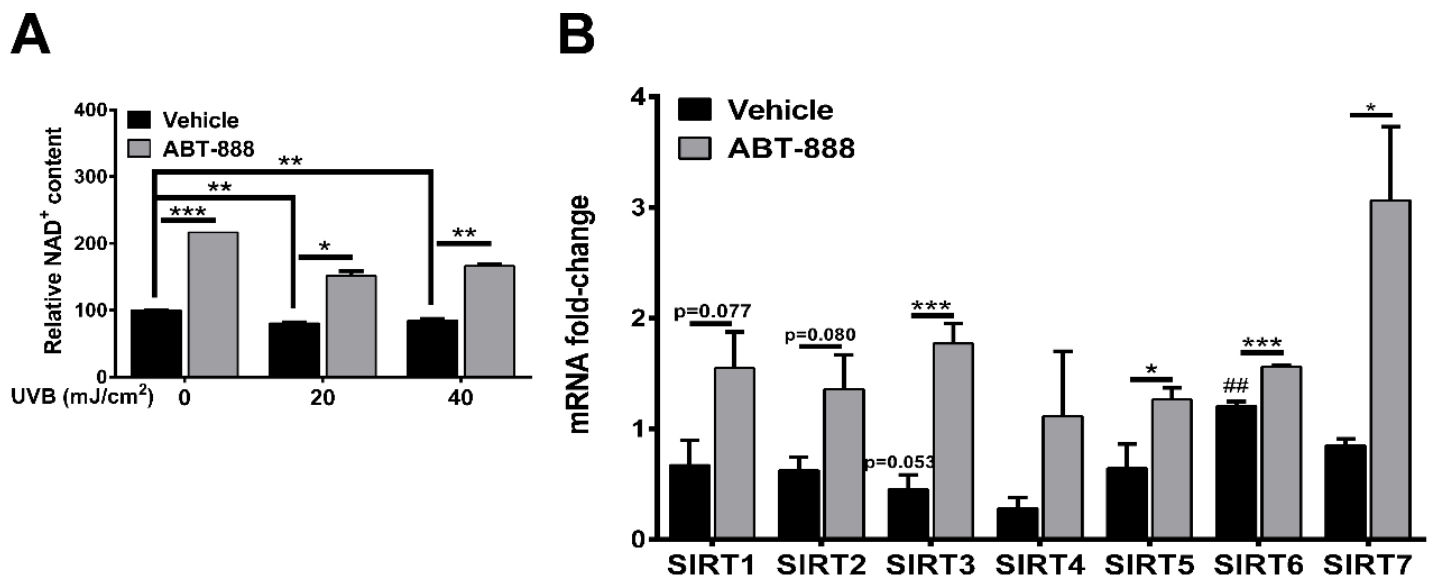

Figure 7. PARP inhibition restores $\mathrm{NAD}^{+}$level and Sirtuin expression. (A) Total cellular $\mathrm{NAD}^{+}$were quantified by colorimetric assay $24 \mathrm{~h}$ after UVB irradiation. Absorbance was measured at $490 \mathrm{~nm}$ $(n=2)$. (B) mRNA expression of the Sirtuin enzyme family $24 \mathrm{~h}$ post-UVB $(40 \mathrm{~mJ}, n=3)$. *; ${ }^{* *}$ and $* * *$ indicate statistically significant difference at $p<0.05$ and $p<0.01, p<0.001$, respectively. \#\# indicate significant difference at $p<0.01$ compared to non-irradiated control. Error bars represent SEM.

\subsection{PARP Inhibition Enhances UVB-Mediated Upregulation of Metabolic Proteins}

To explore the potential mechanisms responsible for elevated oxidative phosphorylation after UVB and PARP inhibition, we checked the expression of metabolic proteins involved in oxidative phosphorylation by Western blot (Figure 8A,B). Consistent with their role in mitochondrial activity, we detected significant increase in ATM, p-ATM, SIRT1, peroxisome proliferator-activated receptor gamma coactivator 1-alpha (PGC1A), AMPK, p-AMPK, p53, p-p53, p-AKT, and p-p70S6K1 (mTOR activity) expression after UVB which was further enhanced by PARP inhibition. The most prominent and statistically significant upregulation in these proteins can be detected after $40 \mathrm{~mJ} / \mathrm{cm}^{2} \mathrm{UVB}$ dose similarly as OXPHOS was increased to two-fold at $p<0.001$. PARPi induced statistically significant difference at 0 and $20 \mathrm{~mJ} / \mathrm{cm}^{2}$ compared to vehicle control similarly as ABT-888 increased OXPHOS as well. PARP1 knockdown also induced upregulation in these proteins compared to siRNA control. 
These results suggest that these proteins switch on oxidative metabolism and their elevated expression may be responsible for higher oxygen consumption after UVB and ABT-888 treatment.
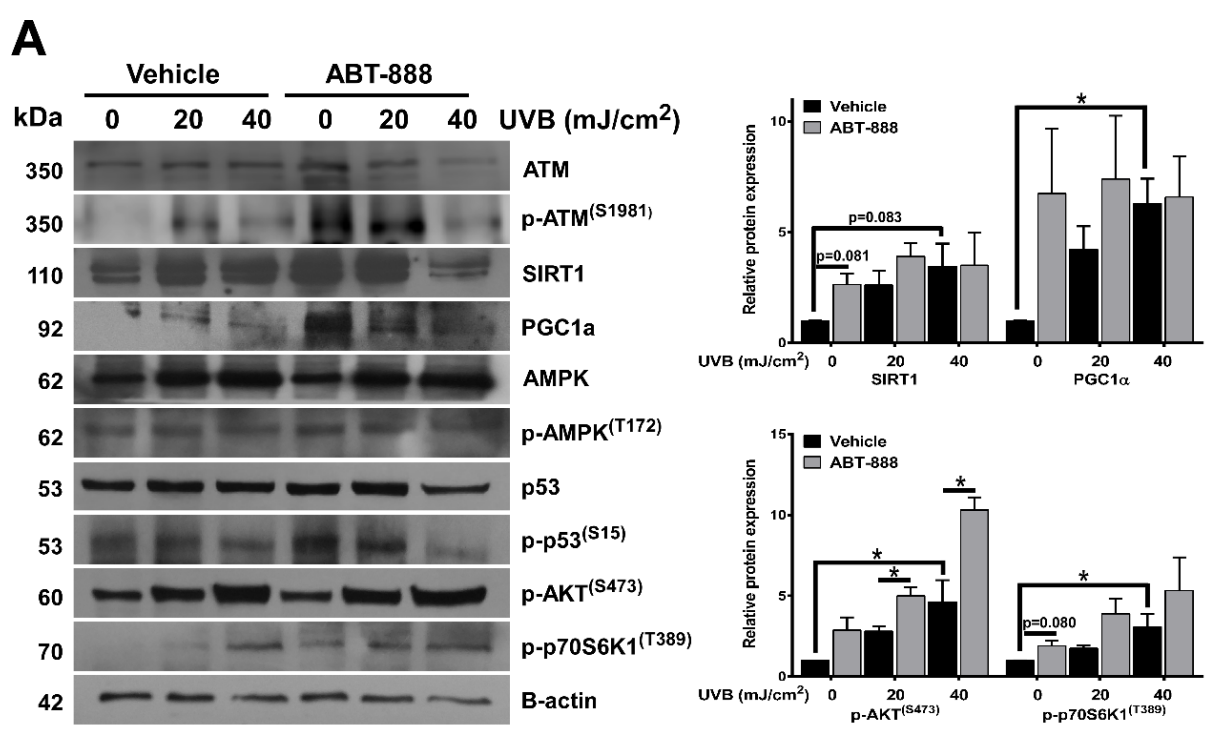

B
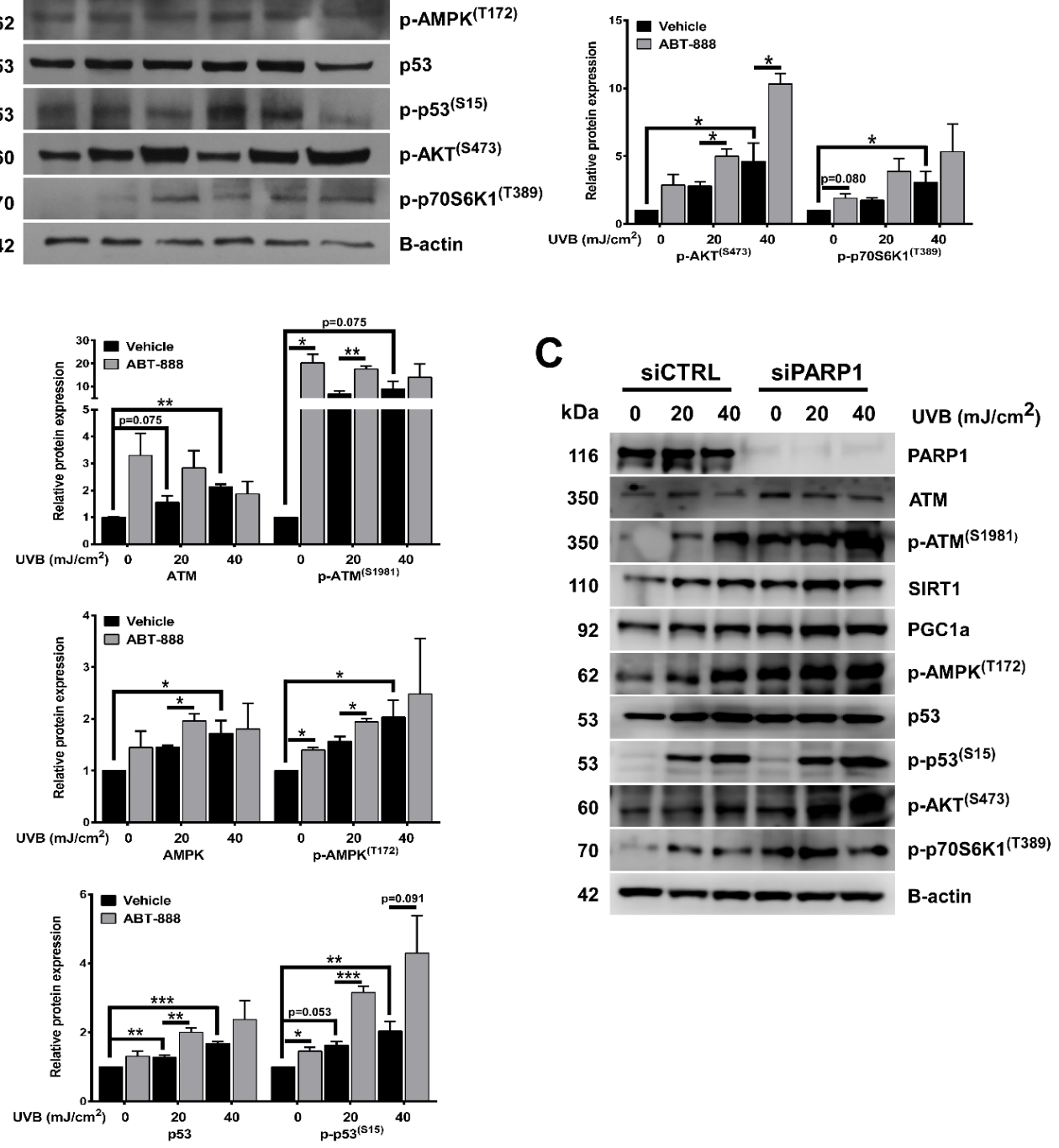

Figure 8. PARP inhibition enhances UVB-mediated upregulation of metabolic proteins. (A) Metabolic proteins involved in oxidative phosphorylation were analyzed in total protein lysates. Protein of interest were normalized to the loading control B-actin. Cells were harvested $24 \mathrm{~h}$ after UVB. Brightness and contrast were adjusted. (B) Densitometric representation of Figure 8A proteins $(n=\min .3)$. (C) Protein expression involved in oxidative phosphorylation was confirmed by PARP1 knockdown. *; ** and ${ }^{* * *}$ indicate statistically significant difference at $p<0.05$ and $p<0.01, p<0.001$, respectively. Error bars represent SEM. 
2.8. PARP Inhibition and UVB-Induced Oxidative Phosphorylation and Autophagy Are Dependent on ATM, AMPK, p53, AKT, and mTOR Activation

To test their requirement for increased oxidative phosphorylation, we applied KU-60019 as an ATM inhibitor (Figure 9A) and ATM siRNA for gene silencing (Figure 10A), compound C as an AMPK inhibitor, Pifithrin-alpha-HBr as a p53 inhibitor, Wortmannin as a phosphoinositide 3-kinase (PI3Ki)/AKT inhibitor and Rapamycin as a mTOR inhibitor (Figure 9A). Chemical inhibition of these proteins led to significant reduction in OXPHOS highlighting their role in mediating metabolic alterations after UVB and PARP inhibition. ATM inhibition (Figure 9B) and ATM knockdown (Figure 10B) also decreased the phosphorylation of AMPK, p53, AKT, and p70S6K1 which suggest that elevation in OXPHOS after UVB is downstream of ATM, which is known as one of the most important players in DNA damage response besides PARP1. Since CPD removal is mediated by the energetically demanding nucleotide excision repair, keratinocytes may try to compensate their increased DNA damage with a more intense mitochondrial activity to facilitate CPD elimination. In this respect, OXPHOS seems to be a beneficial response after UVB. To confirm this hypothesis, we applied inhibitors that decreased (ATMi, AMPKi, p53i, PI3Ki, mTORi) or limit the activity of mitochondrial electron transport chain (oligomycin and rotenone) or inhibits mitochondrial protein synthesis (chloramphenicol) (Figure 9C). Our data show that all these inhibitions led to a more pronounced cell death after UVB which confirms that increased mitochondrial activity bears an adaptive and antiapoptotic response after UVB. We also wanted to explore if UVB and PARPi-triggered general autophagy (Figure 5A,B) by recycling damaged organelles and macromolecules serves to provide metabolites for OXPHOS. To confirm this hypothesis, we tested the ATM, AMPK, p53, PI3K, and $\mathrm{mTOR}$ inhibitors after $40 \mathrm{~mJ} / \mathrm{cm}^{2} \mathrm{UVB}$ that caused the most prominent decrease in oxygen consumption (Figure 9A). Chemical inhibition of these proteins induced significant reduction in LC3B (Figure 9D) and Parkin (Figure 9E) expression similarly as UVB and PARPi-induced OXPHOS decreased after ATM, AMPK, p53, PI3K, and mTOR inhibitors indicating a parallel reduction in oxidative phosphorylation, autophagy, and PARKIN expression (a marker for mitophagy) as well. Reduction in PARKIN expression suggests impaired mitochondrial quality control, allowing the accumulation of damaged mitochondria, corrupting mitochondrial function, eventually leading to decreased OXPHOS. These results together suggest that after UVB and ABT-888 treatment, AMPK, p53, AKT, and mTOR are the main mediators of oxidative phosphorylation downstream of ATM kinase, and autophagy by recycling damaged cellular parts after stress response may provide metabolites to mitochondria and supports OXPHOS after UVB exposure and PARP inhibition.

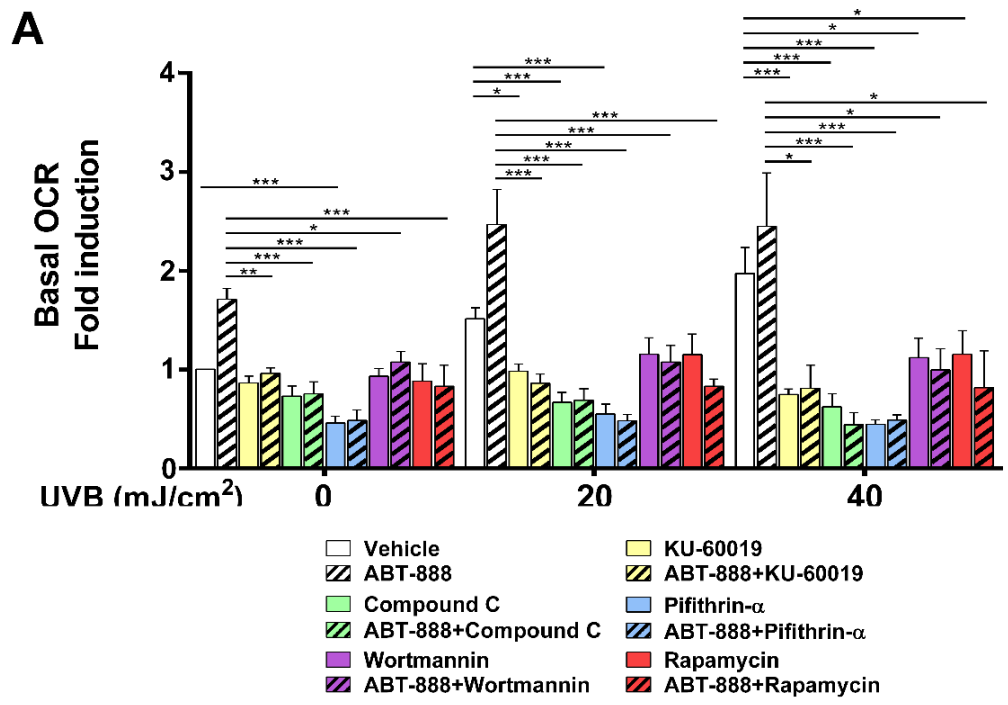

Figure 9. Cont. 
B

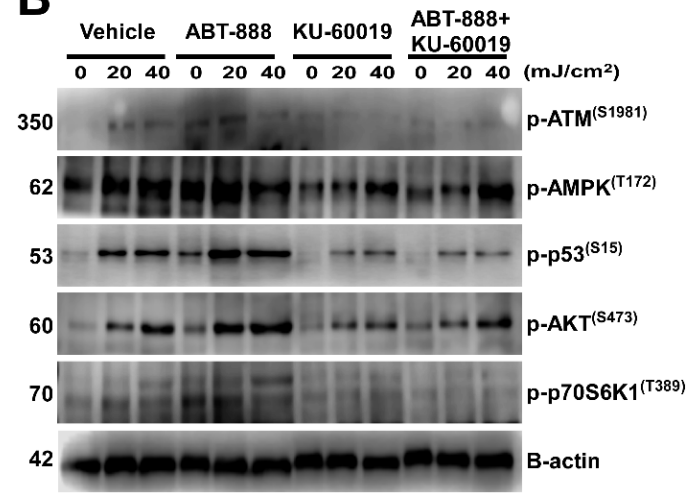

D

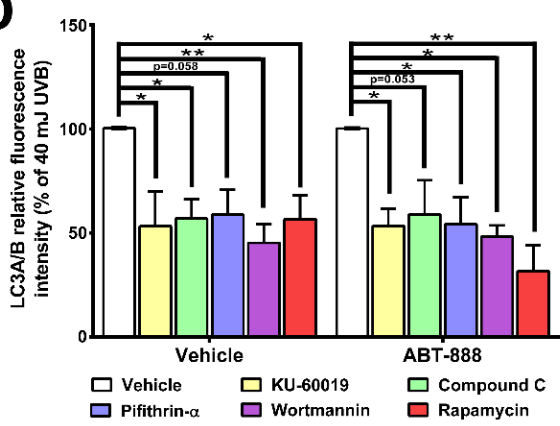

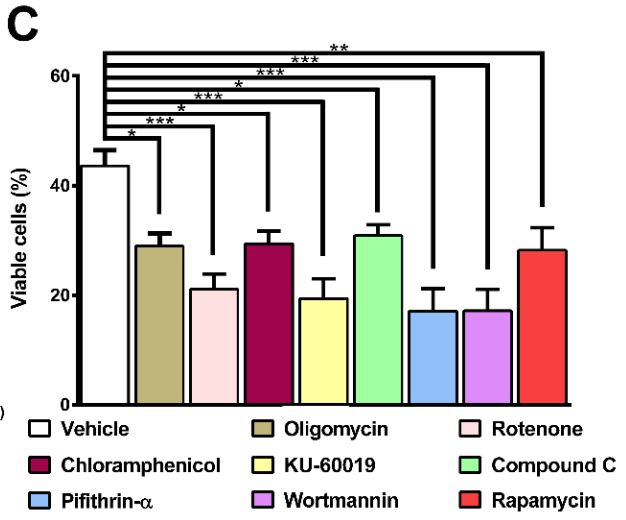

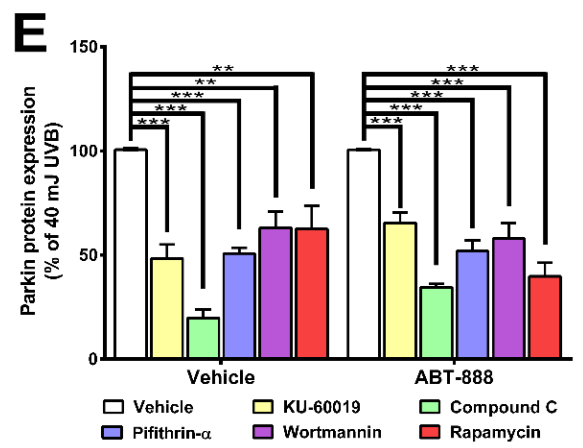

Figure 9. PARP inhibition and UVB-induced oxidative phosphorylation and autophagy are dependent on ATM, AMPK, p53, AKT, and mTOR activation. (A) To determine key proteins involved in mediating mitochondrial changes ATMi (KU-60019), AMPKi (Compound C), p53i (Pifithrin-alpha-HBr), PI3Ki (Wortmannin), and mTORi (Rapamycin) were added to the medium and OCR was measured as in Figure 6C ( $n=$ min.3). (B) ATM downstream signaling pathway was investigated by Western blot with the addition of its pharmacological inhibitors KU-60019 $(n=3)$. Brightness and contrast were adjusted. (C) Cell viability was measured by flow cytometry as in Figure $1 \mathrm{E}$ after $40 \mathrm{~mJ} / \mathrm{cm}^{2} \mathrm{UVB}$ with oligomycin, rotenone, chloramphenicol, ATMi, AMPKi, p53i, PI3Ki, and mTORi ( $n=\min .4)$. To determine the involvement of ATM, AMPK, p53, AKT, and mTOR in the regulation of (D) autophagy and (E) PARKIN expression, we applied their respective pharmacological inhibitors after $40 \mathrm{~mJ} / \mathrm{cm}^{2}$ UVB. $(n=4){ }^{*}{ }^{*}{ }^{* *}$ and ${ }^{* * *}$ indicate statistically significant difference at $p<0.05$ and $p<0.01, p<0.001$, respectively. Error bars represent SEM. ATM: ataxia-telangiectasia-mutated kinase, AMPK: adenosine monophosphate-activated kinase, AKT: protein kinase B, mTOR: mammalian target of rapamycin, OCR: oxygen consumption rate. 
A

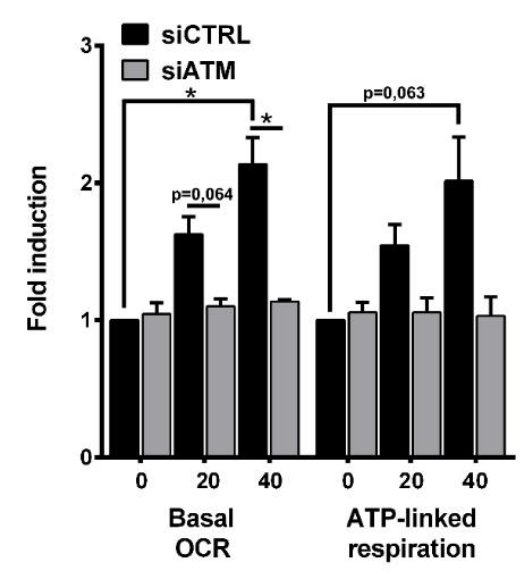

B

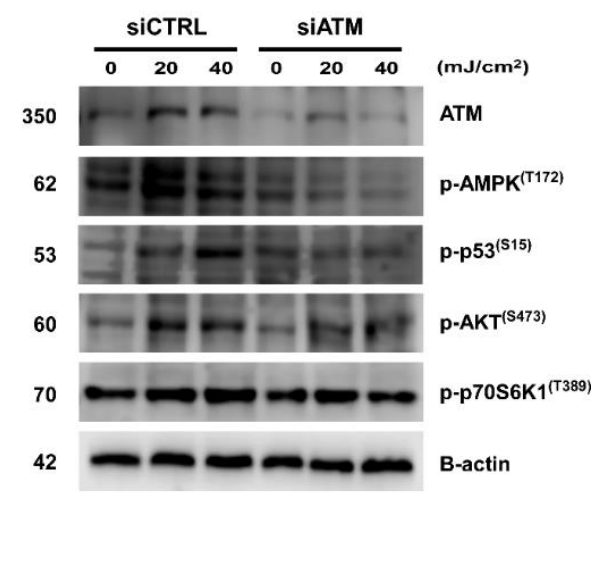

Figure 10. ATM silencing after UVB showed similar results as ATM inhibition by KU-60019. (A) OCR was measured as in Figure 6C $(n=2)$ after ATM knockdown. (B) ATM downstream signaling pathway was investigated by Western blot with ATM silencing $(n=2)$. * indicates statistically significant difference at $p<0.05$. Error bars represent SEM.

\section{Discussion}

In this study, we identified morphological and functional changes of mitochondria after UVB and PARP inhibition. Early after UVB exposure, we detected PAR formation, reflecting PARP activity which was completely suppressed by PARP inhibition. We showed that loss of PARylation caused defective CPD repair compared to the UVB-irradiated cells suggesting impaired NER pathway as several PARP1-intercating partners (DDB1, DDB2, ATM, RAD51, ALC1, XPC) [89-91] have been described so far. Furthermore, PARP1 promotes the establishment of locally relaxed chromatin structure [92] to enable the removal of damaged DNA parts. Therefore, it is logical to assume that PARP inhibition renders chromatin to become compact, blocking not only replication, transcription but also the repair of UVB-induced photoproducts suggesting the particular importance of PARP1 in mediating transcription coupled nucleotide excision repair. Our results show a prolongation in $\mathrm{G}_{2} / \mathrm{M}$ phase of cell cycle after PARPi as described earlier [93-95]. Inhibition of PARP1 was synergistic with UVB with respect to $\mathrm{G}_{2} / \mathrm{M}$ accumulation characteristic of severe DNA damage after $20 \mathrm{~mJ} / \mathrm{cm}^{2} . \mathrm{G}_{2} / \mathrm{M}$ accumulation can also be attributed to PARP trapping, in which inactivated PARP1 remains bound to DNA stalling replication, transcription leading to replicative stress and double-strand breaks [96,97] which make PARP inhibitors cytotoxic in combination with DNA damaging agents $[98,99]$. If DNA damage cannot be repaired, cells try to evade the accumulation of mutations by initiating apoptosis. Since apoptotic response after UVB cannot be ameliorated by PARPi, we can exclude the possibility that UVB-triggered cell death in our model system is PARP1-dependent, it may rather suggest that the accumulated and unrepaired CPDs augments the apoptotic response after PARPi. Long-term survival of keratinocytes revealed that the combined treatment of UVB and PARP inhibition severely reduced cell proliferation even at the non-irradiated conditions possibly suggesting the role of trapped PARP1-DNA complexes preventing cells division. We also detected that loss of PARylation decreased the frequency of mutations in UVB-treated cells as evidenced by decreased number of colonies after ABT- 888 treatment suggesting that PARPi initiate apoptosis of cells with a high content of CPDs. Our results are in accordance with the anti-cancer effect of diverse PARP inhibitors and provide experimental evidence for the photosensitizing effect of PARP inhibitors experienced clinically $[100,101]$. Nevertheless, it is important to know that therapeutic application of PARP inhibitors might be associated with photosensitivity (sunburn) but not with an increased photocarcinogenesis risk.

Emerging evidence suggest that autophagy induction can be coupled to DNA damage response [67]. Accordingly, UVB triggered the accumulation of autophagosomes which corroborates with enhanced 
LC3B expression. PARP inhibition resulted in enhanced autophagosome formation and higher LC3B protein level. The role of PARP1 in the regulation of autophagy is still poorly understood, both autophagy inducer [70] and inhibitory effect of PARP1 [75] can be found in the literature. In our model system, increased autophagosome formation after UVB and PARPi can be attributed to the elevated level of DNA damage (higher CPD content), which serves as a positive signal for autophagy since the initiation of global genome NER (GG-NER) subpathway is controlled by autophagy $[67,68]$.

As Le Brace et al. [28] demonstrated, different DNA damaging agents including UVC which also induce CPD formation as UVB, led to AMPK activation and increased fatty acid oxidation. Similarly to their results, UVB radiation triggered mitochondrial fusion and induced mitochondrial biogenesis, which culminated in enhanced mitochondrial activity and complex metabolic events which were more prominent in PARP-inhibited cells. Increased number of mitochondria and mitochondrial area after UVB irradiation was more robust after PARPi. mRNA expression of mitochondrial biogenesis regulators, increased MTCO1/SDHA ratio, higher mitochondrial mass show similar trends suggesting that elevated mitochondrial content is indeed due to enhanced mitochondrial biogenesis and not defective mitochondrial turnover. By measuring mitochondrial function, we observed that PARP inhibition enhanced the UVB-mediated mitochondrial hyperpolarization, raised cellular ATP level and OXPHOS. Interestingly, we detected neither mitochondrial membrane depolarization nor ATP loss which normally occurs after PARP activation via NAD ${ }^{+}$resynthesis from ATP [102]. Since intracellular ATP concentration is also a regulator in DNA repair and a key factor in the cell's decision to die via apoptosis or necrosis [103], it is likely that this elevation in ATP level is required for the energetically costly nucleotide excision repair to remove UVB-induced photoproducts, and/or necessary for the apoptotic process as seen after staurosporine treatment [104]. Boost in mitochondrial OXPHOS was dependent on ATM, AMPK, p53, AKT, and mTOR phosphorylation since inhibition of them lead to significant reduction in oxygen consumption after both UVB and PARPi. Moreover, enhanced mitochondrial activity seems to induce a beneficial response after DNA damage, since decreasing mitochondrial biogenesis or ameliorating OXPHOS resulted in elevated cell death after UVB irradiation suggesting the protective effect of OXPHOS on cell viability. Inhibition of the ATM, AMPK, p53, PI3K, and mTOR pathways caused significant reduction in LC3A/B and Parkin expression emphasizing their role in autophagy and mitophagy. Decrease in mitophagy and the concomitant impaired mitochondrial quality control may also be an underlying cause for decreased OXPHOS after chemical inhibition of these proteins. We hypothesize that the purpose of autophagy induction after UVB-induced DNA damage is to recycle damaged molecules by fueling mitochondria with metabolites for oxidative phosphorylation as suspected by Dong et al. [105] and autophagy promotes the DNA damage recognition via NER. Since autophagy is an ATP-dependent process and cells must maintain their energy status to promote autophagy, we cannot exclude reciprocal regulation that is the shift toward oxidative metabolism regulates autophagy as described by Thomas et al. [106]. Nonetheless, in our model system it seems obvious that the purpose of autophagy and OXPHOS induction is to promote cell survival after UVB via ATM, AMPK, p53, AKT, and mTOR activation.

So how, increased mitochondrial activity is connected to DNA damage? The UVB-induced photolesions trigger local conformational changes on DNA similarly as seen after etoposide treatment [107] and UVC irradiation [108] which also resulted in increased mitochondrial biogenesis and activity $[18,28]$. Since, PARP-inhibited cells displayed higher level of CPDs compared to UVB-irradiated samples, it seems plausible that CPDs generated on DNA may be a trigger for mitochondrial changes. This is supported by the fact that the phosphorylation status of the main DNA damage responders (ATM, AMPK, p53, AKT, and mTOR) that are activated by UVB become more prominent after PARPi. ATM is mainly activated by DNA double-strand breaks but also a sensor of CPDs [109]. Furthermore, unrepaired CPD lesions in PARPi cells due to PARP trapping may eventually be converted into DNA breaks during replication which is an ultimate trigger for ATM activation. ATM can directly phosphorylate AMPK [110], p53 [111], and AKT [112] and via AKT and AMPK signaling ATM regulates mTOR activity [113], as well to turn on oxidative metabolism. AMPK can also phosphorylate p53 at 
S15 [114], thereby potentiating its activity in enhancing mitochondrial metabolism. Furthermore, it is noteworthy that although cell type-dependently, AMPK [115], p53 [116] AKT [117], and mTOR [118] activation can trigger mitochondrial fusion which may also be a possible explanation for enhanced mitochondrial activity. Since PARP inhibition alone do not induce CPD formation, we must take into account that the PARPi-mediated changes in the non-irradiated cells are mediated by CPD-independent mechanisms either through autophagy induction and/or $\mathrm{NAD}^{+}$prevention. However, we can exclude the involvement of $\mathrm{NAD}^{+}$in the regulation of mitochondrial function after $\mathrm{UVB}$, since morphological alteration of mitochondria and oxidative phosphorylation do not show similar changes as intracellular $\mathrm{NAD}^{+}$availability after UVB irradiation.

\section{Materials and Methods}

\subsection{Chemicals}

All chemicals were obtained from Sigma-Aldrich (St. Louis, MO, USA) unless stated otherwise.

\subsection{Cell Culture}

Human immortalized keratinocyte-derived (HaCaT) cell line were cultured in a T75 flask, as previously described [119] using $4500 \mathrm{mg} / \mathrm{L}$ Dulbecco's modified eagle media (DMEM) Glutamax supplement (Thermo Fisher Scientific, Waltham, MA, USA) containing 10\% heat-inactivated fetal bovine serum (FBS) and $0.5 \%$ antibiotic/antimycotic solution. For HPRT mutation assay, Chinese hamster ovary $(\mathrm{CHO})$ cells were used as described in Section 4.7. Cells were maintained in a humidified incubator at $37^{\circ} \mathrm{C}$ with $5 \% \mathrm{CO}_{2}$ atmosphere.

\subsection{Cell Treatment}

Cells were harvested with trypsin-EDTA (Biosera, Budapest, Hungary) then seeded in 12-well plate in 200,000 cell/well density (unless stated otherwise), and allowed to adhere for at least $12 \mathrm{~h}$. At $80 \%$ confluence, cells were pretreated with the PARP inhibitor veliparib (ABT-888) (Selleckchem, Houston, TX, USA) at a final concentration of $25 \mu \mathrm{M}$. For detection of cell death, autophagy, mitophagy, and OXPHOS, the following inhibitors were used: ATMi: $6 \mu \mathrm{M}$ KU-60019 (Adooq, Irvine, CA, USA), AMPKi: $2.5 \mu \mathrm{M}$ compound C (Selleckchem), p53i: $30 \mu \mathrm{M}$ pifithrin-alpha-HBr (AdooQ), mTORi: $300 \mathrm{nM}$ rapamycin (AdooQ), PI3Ki: $300 \mathrm{nM}$ wortmannin (AdooQ), mitochondrial activity inhibitors: $5 \mu \mathrm{M}$ oligomycin, and $500 \mathrm{nM}$ rotenone. To inhibit mitochondrial protein synthesis and hamper mitochondrial function chloramphenicol (AdooQ) $(25 \mu \mathrm{M})$ was used. For UVB irradiation, cells were covered with $400 \mu \mathrm{l}$ pre-warmed Dulbecco's phosphate-buffered saline (DPBS) (Lonza, Walkersville, MD, USA) and were subjected to 20 or $40 \mathrm{~mJ} / \mathrm{cm}^{2}$ UVB using two UVB broadband tubes (TL-20W/12 RS; Philips, Eindhoven, The Netherlands). Immediately after irradiation, the old medium was placed back on the cells to evade metabolic perturbations and cells were further cultured for $24 \mathrm{~h}$. Controls were covered with tin foil during irradiation. The proper UV dose was measured with a UVX digital radiometer (UVP Inc., San Gabriel, CA, USA). Detached, dead cells were excluded from the experiments except for cell viability.

\subsection{Gene Silencing}

On-target plus SMARTpool PARP1 and ATM siRNA sequence was purchased from Dharmacon Research, Inc. (Lafayette, CO). Non-targeting siRNA (Dharmacon) was used as a control. HaCaT cells were seeded into 12-well plates in complete high-glucose DMEM containing 10\% FBS without antibiotics. DharmaFECT transfection reagent (Dharmacon) in tube 1 and siRNA in $1 \times$ siRNA buffer (Dharmacon) in tube 2 was diluted in serum and antibiotics-free DMEM and incubated at room temperature for $5 \mathrm{~min}$. The two mixtures were combined and incubated further for $20 \mathrm{~min}$ and added to the cells at a final siRNA concentration of $50 \mathrm{nM}$. After $48 \mathrm{~h}$, cells were washed with DPBS, irradiated 
with UVB, and the medium was replaced with a complete growth medium. Silencing efficiency was determined by Western blotting $24 \mathrm{~h}$ post-UVB.

\subsection{Cell Viability and Proliferation}

Over the $24 \mathrm{~h}$ period following UVB exposure cell viability was determined by dead cell apoptosis kit containing propidium iodide/Alexa Fluor 488-conjugated Annexin V (Invitrogen, Carlsbad, CA, USA) according to the manufacturer's instruction. Labelled cells were analyzed by flow cytometry with a FACSCalibur (Becton Dickinson, San Jose, CA, USA) measuring the fluorescence emission in FL1 $(530 \mathrm{~nm})$ and FL3 (>575 nm). Double negative cells represent viable cells. For data collection and evaluation CellQuest software 5.2 (Becton Dickinson) and Flowjo single cell analysis software were used.

Cell proliferation was determined by clonogenic assay. Cells were seeded in $100 \mathrm{~mm}$ Petri dish at 5000 cells/dish and were allowed to grow for 10 days. The medium was replaced each day to monitor the long-term effect of cell treatments. Ten days later, cells were washed with PBS, fixed with 100\% methanol, and stained with May-Grünwald-Giemsa solution (Histolab Products, Västra Frölunda, Sweden).

\subsection{Cell Cycle Analysis}

Cell cycle progression was quantified using propidium iodide (PI) staining. Briefly, cells were trypsinized, fixed with ice-cold $96 \%$ ethanol for $10 \mathrm{~min}$, washed twice with PBS, and permeabilized with $0.1 \%$ Triton X-100. After extensive washing, cells were incubated in PBS solution containing $0.5 \mathrm{mg} / \mathrm{mL}$ RNase at $37^{\circ} \mathrm{C}$ for $1 \mathrm{~h}$ and counted for cell number normalization. For cell staining, PI was used a final concentration of $20 \mu \mathrm{g} / \mathrm{mL}$. Unbound PI was eliminated by washing with PBS and doublet discrimination was performed. To determine DNA content samples were analyzed on the $\mathrm{x}$-axis in FL2-A channel using a FACSCalibur flow cytometer.

\subsection{HPRT Mutation Assay}

CHO cells were cultured in a HAT (hypoxanthine-aminopterin-thymidine) medium in T75 flask for one week to remove cells with pre-existing HPRT mutation. After a week, HAT medium was replaced with complete DMEM and cells were allowed to recover for three days. Thereafter, $\mathrm{CHO}$ cells were seeded into a 6-well plate and allowed to adhere for $24 \mathrm{~h}$. Next day, cells were cultured with or without $25 \mu \mathrm{M}$ ABT- 888 and UVB irradiation was carried out with 10 or $20 \mathrm{~mJ} / \mathrm{cm}^{2}$ dose. CHO cells were cultured further for one week in DMEM with sub-culturing three times a week. After a week, cells were trypsinized, counted, distributed to $100 \mathrm{~mm}$ Petri dish at concentration of $5 \times 10^{4}$ per Petri dish in selection medium supplemented with $5 \mu \mathrm{g} / \mathrm{mL}$ 6-thioguanine (6-TG), and incubated for 10 days. After 10 days, cells were washed with PBS, fixed with $100 \%$ methanol for $10 \mathrm{~min}$, and stained with May-Grünwald-Giemsa solution. Mutant colonies were counted.

\subsection{CPD-Specific Enzyme-Linked Immunosorbent Assay (ELISA)}

Genomic DNA was extracted from HaCaT cells using a Purelink Genomic DNA mini kit (Thermo Fisher Scientific) according to the manufacturer's instruction. For quantitative detection of CPDs, direct ELISA was applied as previously described [120].

\subsection{Real-Time Quantitative RT-PCR}

Total RNA was isolated using guanidinium isothiocyanate-phenol-chloroform extraction (TRI reagent) (MRC, Cincinnati, OH, USA) according to the protocol by Chomczynski et al. [121]. RNA concentration and purity were determined spectrophotometrically. RNA was deprived of DNA contamination by DNase I treatment (Fermentas, St. Leon-Rot, Germany). Reverse transcription (RT) was carried out using the high-capacity cDNA reverse transcription kit (Applied Biosystems, Foster 
City, CA, USA) according to the manufacturer's instruction. Real-time RT-PCR analysis was performed by the SYBR green method using a Lightcyler 480 II (Roche Diagnostics). Reactions were carried out in 384-well optical plates. RNA expression values were determined by $1.8^{-\Delta C T}$ method and normalized for the housekeeping gene SDHA and phosphoglycerate kinase 1 (PGK1) [122]. Primer pairs and corresponding sequences are listed in Supplementary Table S1 "Primer pairs used in the study".

\subsection{Western Blot}

HaCaT cells were pelleted by mild centrifugation at $1500 \mathrm{rpm}$ for $5 \mathrm{~min}$ at $4{ }^{\circ} \mathrm{C}$. The pellets were lysed on ice with RIPA buffer supplemented with a protease inhibitor cocktail in 1:1000. After 5 min incubation on ice, supernatants were obtained by centrifugation of the lysates at 15,000 rpm for $10 \mathrm{~min}$ at $4{ }^{\circ} \mathrm{C}$. The concentration of proteins was determined using Pierce BCA assay kit (Thermo Fisher Scientific). The lysates were mixed with 5X loading buffer (Bromophenol blue (0.25\%), $\beta$-Mercaptoethanol (5\%), Glycerol (50\%), SDS (sodium dodecyl sulfate; 10\%), Tris- $\mathrm{HCl}(0.25 \mathrm{M}, \mathrm{pH} 6.8)$ ), boiled for $10 \mathrm{~min}$ at $100{ }^{\circ} \mathrm{C}$ and subjected to $7.5 \%, 10 \%$, or $12.5 \%$ SDS polyacrylamide gel electrophoresis. Proteins were transferred onto nitrocellulose membrane (Bio-Rad, Hercules, CA, USA). The membranes were blocked in TBST ( $0.05 \%$ Tween 20 in TBS buffer) containing $5 \%$ bovine serum albumin (BSA). The incubation with primary antibodies was carried out overnight at $4{ }^{\circ} \mathrm{C}$ followed by washing. Horseradish peroxidase (HRP)-conjugated goat anti-mouse or anti-rabbit IgG was used as a secondary antibody (Bio-Rad) at room temperature for $1 \mathrm{~h}$. Proteins were visualized by ECL Prime Western blotting detection reagent (Thermo Fisher Scientific). All the antibodies used for Western blotting were listed in Supplementary Table S2 "Primer antibodies used in the study". Bands were quantified using the ImageJ open source software [123] (version 1.51k, National Institutes of Health, Bethesda, MD). Proteins of interest were normalized for $\beta$-actin. Sample uncut blots are provided on Supplementary Figure S2.

\subsection{Mitochondrial Mass}

$24 \mathrm{~h}$ post-UVB, Mitotracker Green (Thermo Fisher Scientific) were added to the culture medium at a final concentration of $100 \mathrm{nM}$ and cells were incubated at $37^{\circ} \mathrm{C}$ for $30 \mathrm{~min}$. Following incubation, cells were washed with PBS and harvested by trypsinization and then placed on ice. The fluorescence intensity of cells stained with Mitotracker Green was analyzed in a FL1 channel using flow cytometry.

\subsection{Determination of Mitochondrial Membrane Potential}

HaCaT cells were seeded in a culture plate and next day subjected to UVB. $24 \mathrm{~h}$ post-UVB, $3,3^{\prime}$-dihexyloxacarbocyanine iodide $\left(\mathrm{DiOC}_{6}(3)\right)$ (Invitrogen) were added to the culture medium at a final concentration of $40 \mathrm{nM}$ and cells were further incubated at $37^{\circ} \mathrm{C}$ for $30 \mathrm{~min}$. Following incubation, cells were washed with PBS and harvested by trypsinization and then placed on ice. The fluorescence intensity of cells stained with $\operatorname{DiOC}_{6}(3)$ was analyzed in FL1 channel using flow cytometry.

\subsection{Determination of Mitochondrial Ultrastructure, Mitochondrial Number, and Area by Transmission Electron Microscopy (TEM)}

After cell treatment, cells were washed with DPBS, harvested by trypsinization, pelleted, and fixed by $3 \%$ glutaraldehyde (EMS, Hatfield, PA, USA) in $0.1 \mathrm{M}$ cacodylic acid (EMS) buffer complemented by $5 \%$ sacharose for $2 \mathrm{~h}$. After washing steps in $0.1 \mathrm{M}$ cacodylic acid buffer, cells were osmificated in $1 \% \mathrm{OsO}_{4}$, dehydrated in ascending alcohol row, namely $50 \%$ for $2 \times 10^{\prime}, 70 \%$ for $2 \times 10^{\prime}, 96 \%$ for $2 \times 15^{\prime}$, absolute ethanol for $3 \times 20^{\prime}$, and propylene oxide for $2 \times 10^{\prime}$. Then, overnight a durcupan araldite treatment was used for embedding the samples. Encapsulation occurred in an incubator for $48 \mathrm{~h}$ and ultrathin section was made by Leica EM UC7 ultramicrotome (Leica Microsystems, GmbH, Wetzlar, Germany). Standard contrasting was performed by uranyl acetate (EMS) and Reynolds' lead citrate solution. High resolution TEM images was made by the Jeol JEM 1010 electron microscope and software (JEOL Inc. Peabody, MA, USA). 


\subsection{Assessment of Mitochondrial Morphology and Autophagy by Confocal Microscopy}

Cells were plated on glass slides in a 24 -well plate and $24 \mathrm{~h}$ post-UVB cells were stained with $100 \mathrm{nM}$ Mitotracker Red CMXRos (Thermo Fisher Scientific) dye at $37^{\circ} \mathrm{C}$ for $30 \mathrm{~min}$. Cells were washed with PBS, fixed with 3.7\% paraformaldehyde solution at room temperature for $10 \mathrm{~min}$ and permeabilized with $0.2 \%$ Triton X-100 for $10 \mathrm{~min}$. After washing with PBS, blocking was performed by $1 \%$ BSA-containing PBS at $37^{\circ} \mathrm{C}$ for $1 \mathrm{~h}$. Cells were incubated with an Alexa Fluor 488-conjugated LC3A/B antibody diluted in 1\% BSA (1:50) at $4{ }^{\circ} \mathrm{C}$ overnight in a humid chamber. Next day, slides were washed three times with PBS. Prior to imaging, cells were stained with a mounting medium with DAPI and analyzed by confocal microscopy using 60x oil immersion objective. Background subtraction, noise reduction, local contrast enhancement, unsharp mask, and bandpass filtering were applied on raw images for better image quality and proper image evaluation [124]. Processed images were analyzed by ImageJ software. Mitochondrial complexity was calculated from confocal microscopic images and was defined as a form factor ((Perimeter ${ }^{2} /\left(4 \pi^{*}\right.$ area $\left.)\right)$. For flow cytometric analysis of autophagy, cells were washed with PBS and harvested by trypsinization. Fixation, permeabilization, and blocking were carried out as described above. Cells were incubated with Alexa Fluor 488-conjugated LC3A/B antibody using 1:500 dilution at $4{ }^{\circ} \mathrm{C}$ overnight. Next day, after extensive washing, cells were analyzed for Alexa-488 fluorescence intensity in FL1 channel by flow cytometry.

\subsection{Measurement of Citrate Synthase Activity}

For determination of citrate synthase activity, a citrate synthase assay kit was used according to the manufacturer's instruction. Optical density changes by kinetic program was determined at $412 \mathrm{~nm}$ using microplate reader. Values were normalized to total protein concentration.

\subsection{Analysis of Oxygen Consumption and Extracellular Acidification}

Oxygen consumption (OCR) and extracellular acidification rate (ECAR) was measured using an XF96 extracellular flux analyzer (Seahorse Bioscience, North Billerica, MA, USA). The rate of oxygen consumption indicates oxidative phosphorylation, whereas ECAR represent lactic acid formed during glycolysis. Cells were seeded in a XF96 cell culture plate at 10,000 cell/well density. One hour prior to the assay, culture medium was replaced with unbuffered DMEM (Seahorse Bioscience) supplemented with $10 \mathrm{mM}$ glucose and then cells were equilibrated in a $\mathrm{CO}_{2}$-free incubator for $1 \mathrm{~h}$. After four measurements of oxygen consumption, oligomycin and antimycin A were subsequently injected to determine mitochondria-linked ATP production and basal OCR, respectively. All OCR and ECAR values were normalized to the total protein obtained from cells lysed by $1 \mathrm{M} \mathrm{NaOH}$.

\subsection{Determination of $N A D^{+}$Level}

The colorimetric assay for $\mathrm{NAD}^{+} / \mathrm{NADH}$ ratio determination was purchased from Biovision (Mountain View, CA, USA). Cells were washed with PBS two times and harvested by a trypsin-EDTA solution and pelleted by mild centrifugation. The pellet was extracted with $\mathrm{NAD}^{+}$or NADH extraction buffer and exposed to freeze/thaw cycles. Samples were spun and the supernatant was transferred to a 96-well plate for $\mathrm{NAD}^{+} / \mathrm{NADH}$ assays. For $\mathrm{NAD}^{+}$determination, half of the samples were transferred into another tube and $\mathrm{NAD}^{+}$was decomposed by heating samples at $60^{\circ} \mathrm{C}$. Finally, working reagent was added to the samples, and optical density was determined at $450 \mathrm{~nm}$. Optical density of the standard curve and samples was used to calculate $\mathrm{NAD}^{+}$content. Values were normalized to total protein concentration.

\subsection{Measurement of ATP Content}

For determination of ATP level, an ATP colorimetric/fluorometric assay purchased from Biovision was used according to the manufacturer. Optical density was determined at $570 \mathrm{~nm}$ using a microplate reader. Values were normalized to total protein concentration. 


\title{
4.19. Statistical Analysis
}

Statistical analysis was carried out by the Kolmogorov-Smirnov test to assess the normality of the population. The frequency of mitochondrial morphological subtypes (fragmented, intermediate, and tubular) was calculated by $\mathrm{chi}^{2}$ and Ficher's exact test. To assess the statistical significance between untreated and differently treated groups, ANOVA complemented by Dunnett's post-hoc test was used. The comparison of two groups was applied by an independent $t$-test. All data are reported as mean \pm SEM. A $p<0.05$ was considered statistically significant. Statistical significance was determined by the GraphPad Prism 7 (GraphPad Software Inc., San Diego, CA, USA) and SPSS 25 software. (SPSS package for Windows, Release 25.; SPSS, Chicago, IL, USA).

\section{Conclusions}

Our results provide new information about the role of ATM and PARP1 proteins in the regulation of mitochondrial morphology and function after UVB irradiation. Moreover, it suggests that UVB and PARPi-caused elevation of oxidative phosphorylation is mediated by the complex interplay of metabolic sensors including ATM, AMPK, p53, AKT, and mTOR which are the main mediators that connect DNA damage with oxidative metabolism and autophagy.

Data Availability: All primary data is uploaded to https:/figshare.com/s/49fbcd8cfd5802ea15f9 (DOI: 10.6084/m9.figshare.8107727).

Supplementary Materials: The following are available online at http://www.mdpi.com/2072-6694/12/1/5/s1, Figure S1: Uncut PAR (10H) Western blot, Figure S2: Sample uncut blots, Table S1: Primer pairs used in the study, Table S2: Primary antibodies used in the study.

Author Contributions: Original draft preparation, investigation, methodology, C.H.; Writing—review and editing, G.B.; Methodology, E.F.; Investigation, methodology, G.N.K.; Resources, M.A.; Investigation, methodology, T.J.; Formal analysis, E.A.J.; Methodology, L.J.; Writing — review and editing, G.P.; Writing-review and editing, G.E.; Conceptualization, writing — review and editing, resources, P.B.; Project administration, funding acquisition, É.R. All authors have read and agreed to the published version of the manuscript.

Funding: This work was supported by the European Union and the European Regional Development Fund GINOP-2.3.2-15-2016-00005 and was supported by grants from NKFIH K123975, C129074, NKFIH K120206, Momentum program and NM-26/2019 of the Hungarian Academy of Sciences and the University of Debrecen. The project is co-financed by the University of Debrecen (OTKA Bridging Fund). Bolyai Janos Research Scholarship (J.T.). Szodoray Lajos and Magyary Zoltán Funds by Hungarian Academy of Science and the European Union and the State of Hungary, co-financed by the European Social Funding. Fund in the framework of TÁMOP 4.2.4.A/2-11-1-2012-0001 "National Excellence Program" (J.T.). The research was financed by the Higher Education Institutional Excellence Programme (NKFIH-1150-6/2019) of the Ministry of Innovation and Technology in Hungary, within the framework of the Biotechnology thematic programme of the University of Debrecen.

Conflicts of Interest: The authors declare no conflict of interest. G.P. is a consultant for ADC Therapeutics and Buffalo Biolabs. The funders had no role in the design of the study; in the collection, analyses, or interpretation of data; in the writing of the manuscript, or in the decision to publish the results.

\author{
Abbreviations \\ CPD cyclobutane pyrimidine dimer \\ PAR poly (ADP-ribose) polymer \\ PARP1 poly (ADP-ribose) polymerase 1 \\ ATM kinase ataxia-telangiectasia-mutated kinase \\ AMPK adenosine monophosphate-activated kinase \\ mTOR mammalian target of rapamycin \\ p70S6K1 ribosomal protein S6 kinase beta-1 \\ HPRT hypoxanthine-guanine phosphoribosyltransferase \\ PGC1A peroxisome proliferator activated receptor gamma coactivator-1 alpha
}




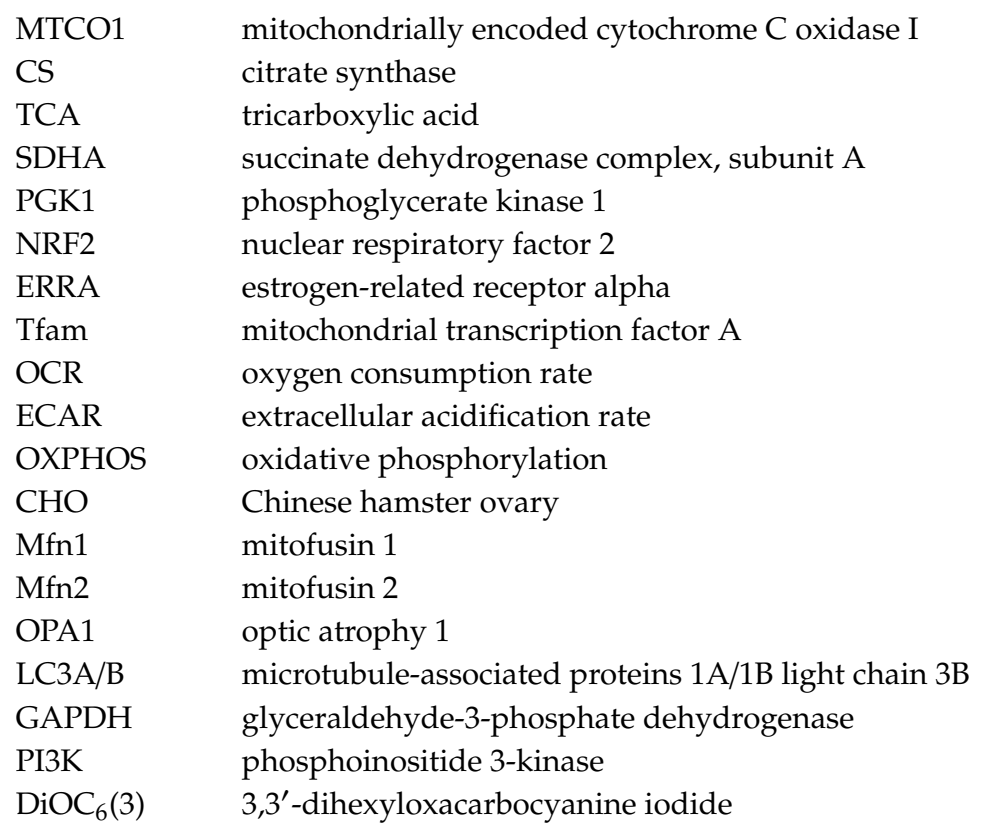

\section{References}

1. Jornayvaz, F.R.; Shulman, G.I. Regulation of mitochondrial biogenesis. Essays Biochem. 2010, 47, 69-84. [PubMed]

2. Dominy, J.E.; Puigserver, P. Mitochondrial biogenesis through activation of nuclear signaling proteins. Cold Spring Harb. Perspect. Biol. 2013, 5, a015008. [CrossRef] [PubMed]

3. Suliman, H.B.; Piantadosi, C.A. Mitochondrial quality control as a therapeutic target. Pharmacol. Rev. 2016, 68, 20-48. [CrossRef] [PubMed]

4. Mears, J.A. Mitochondrial biogenesis and quality control. In The Structural Basis of Biological Energy Generation; Hohmann-Marriott, M.F., Ed.; Springer: Dordrecht, The Netherlands, 2014; pp. 451-476.

5. Westermann, B. Bioenergetic role of mitochondrial fusion and fission. Biochim. Biophys. Acta (BBA) Bioenerg. 2012, 1817, 1833-1838. [CrossRef]

6. Suárez-Rivero, J.M.; Villanueva-Paz, M.; de la Cruz-Ojeda, P.; de la Mata, M.; Cotán, D.; Oropesa-Ávila, M.; de Lavera, I.; Álvarez-Córdoba, M.; Luzón-Hidalgo, R.; Sánchez-Alcázar, J.A. Mitochondrial dynamics in mitochondrial diseases. Diseases 2016, 5, 1. [CrossRef]

7. Feichtinger, R.G.; Sperl, W.; Bauer, J.W.; Kofler, B. Mitochondrial dysfunction: A neglected component of skin diseases. Exp. Dermatol. 2014, 23, 607-614. [CrossRef]

8. Clayton, D.A.; Doda, J.N.; Friedberg, E.C. The absence of a pyrimidine dimer repair mechanism in mammalian mitochondria. Proc. Natl. Acad. Sci. USA 1974, 71, 2777-2781. [CrossRef]

9. LeDoux, S.P.; Wilson, G.L.; Beecham, E.J.; Stevnsner, T.; Wassermann, K.; Bohr, V.A. Repair of mitochondrial DNA after various types of DNA damage in chinese hamster ovary cells. Carcinogenesis 1992, 13, 1967-1973. [CrossRef]

10. Krutmann, J.; Schroeder, P. Role of mitochondria in photoaging of human skin: The defective powerhouse model. J. Investig. Dermatol. Symp. Proc. 2009, 14, 44-49. [CrossRef]

11. Naidoo, K.; Hanna, R.; Birch-Machin, M.A. What is the role of mitochondrial dysfunction in skin photoaging? Exp. Dermatol. 2018, 27, 124-128. [CrossRef]

12. Takeuchi, H.; Fujimoto, A.; Hoon, D.S. Detection of mitochondrial DNA alterations in plasma of malignant melanoma patients. Ann. N. Y. Acad. Sci. 2004, 1022, 50-54. [CrossRef] [PubMed]

13. Yang, J.H.; Lee, H.C.; Chung, J.G.; Wei, Y.H. Mitochondrial DNA mutations in light-associated skin tumors. Anticancer Res. 2004, 24, 1753-1758.

14. Durham, S.E.; Krishnan, K.J.; Betts, J.; Birch-Machin, M.A. Mitochondrial DNA damage in non-melanoma skin cancer. Br. J. Cancer 2003, 88, 90. [CrossRef] [PubMed]

15. Scheibye-Knudsen, M.; Croteau, D.L.; Bohr, V.A. Mitochondrial deficiency in cockayne syndrome. Mech. Ageing Dev. 2013, 134, 275-283. [CrossRef] [PubMed] 
16. Fang, E.F.; Scheibye-Knudsen, M.; Brace, L.E.; Kassahun, H.; SenGupta, T.; Nilsen, H.; Mitchell, J.R.; Croteau, D.L.; Bohr, V.A. Defective mitophagy in xpa via parp-1 hyperactivation and nad(+)/sirt1 reduction. Cell 2014, 157, 882-896. [CrossRef]

17. Croteau, D.L.; Rossi, M.L.; Canugovi, C.; Tian, J.; Sykora, P.; Ramamoorthy, M.; Wang, Z.M.; Singh, D.K.; Akbari, M.; Kasiviswanathan, R.; et al. Recql4 localizes to mitochondria and preserves mitochondrial DNA integrity. Aging Cell 2012, 11, 456-466. [CrossRef]

18. Fu, X.; Wan, S.; Lyu, Y.L.; Liu, L.F.; Qi, H. Etoposide induces atm-dependent mitochondrial biogenesis through ampk activation. PLoS ONE 2008, 3, e2009. [CrossRef]

19. Fang, E.F.; Scheibye-Knudsen, M.; Chua, K.F.; Mattson, M.P.; Croteau, D.L.; Bohr, V.A. Nuclear DNA damage signalling to mitochondria in ageing. Nat. Rev. Mol. Cell Biol. 2016, 17, 308-321. [CrossRef]

20. Hong, S.J.; Dawson, T.M.; Dawson, V.L. Nuclear and mitochondrial conversations in cell death: Parp-1 and aif signaling. Trends Pharmacol. Sci. 2004, 25, 259-264. [CrossRef]

21. Bai, P. Biology of poly(adp-ribose) polymerases: The factotums of cell maintenance. Mol. Cell 2015, 58, 947-958. [CrossRef] [PubMed]

22. Luo, X.; Kraus, W.L. On par with parp: Cellular stress signaling through poly(adp-ribose) and parp-1. Genes Dev. 2012, 26, 417-432. [CrossRef] [PubMed]

23. Aguilar-Quesada, R.; Munoz-Gamez, J.A.; Martin-Oliva, D.; Peralta, A.; Valenzuela, M.T.; Matinez-Romero, R.; Quiles-Perez, R.; Menissier-de Murcia, J.; de Murcia, G.; Ruiz de Almodovar, M.; et al. Interaction between atm and parp-1 in response to DNA damage and sensitization of atm deficient cells through parp inhibition. BMC Mol. Biol. 2007, 8, 29. [CrossRef] [PubMed]

24. Valenzuela, M.T.; Guerrero, R.; Núñez, M.I.; Ruiz de Almodóvar, J.M.; Sarker, M.; de Murcia, G.; Oliver, F.J. Parp-1 modifies the effectiveness of p53-mediated DNA damage response. Oncogene 2002, 21, 1108. [CrossRef] [PubMed]

25. Okuda, A.; Kurokawa, S.; Takehashi, M.; Maeda, A.; Fukuda, K.; Kubo, Y.; Nogusa, H.; Takatani-Nakase, T.; Okuda, S.; Ueda, K.; et al. Poly(adp-ribose) polymerase inhibitors activate the p53 signaling pathway in neural stem/progenitor cells. BMC Neurosci. 2017, 18, 14. [CrossRef] [PubMed]

26. Berger, N.A. Poly(adp-ribose) in the cellular response to DNA damage. Radiat. Res. 1985, 101, 4-15. [CrossRef] [PubMed]

27. Zhou, J.; Ng, S.; Huang, Q.; Wu, Y.T.; Li, Z.; Yao, S.Q.; Shen, H.M. Ampk mediates a pro-survival autophagy downstream of parp-1 activation in response to DNA alkylating agents. FEBS Lett. 2013, 587, 170-177. [CrossRef] [PubMed]

28. Brace, L.E.; Vose, S.C.; Stanya, K.; Gathungu, R.M.; Marur, V.R.; Longchamp, A.; Treviño-Villarreal, H.; Mejia, P.; Vargas, D.; Inouye, K.; et al. Increased oxidative phosphorylation in response to acute and chronic DNA damage. NPJ Aging Mech. Dis. 2016, 2, 16022. [CrossRef]

29. Pantovic, A.; Krstic, A.; Janjetovic, K.; Kocic, J.; Harhaji-Trajkovic, L.; Bugarski, D.; Trajkovic, V. Coordinated time-dependent modulation of ampk/akt/mtor signaling and autophagy controls osteogenic differentiation of human mesenchymal stem cells. Bone 2013, 52, 524-531. [CrossRef]

30. Tao, R.; Gong, J.; Luo, X.; Zang, M.; Guo, W.; Wen, R.; Luo, Z. Ampk exerts dual regulatory effects on the pi3k pathway. J. Mol. Signal. 2010, 5, 1. [CrossRef]

31. Bai, P.; Nagy, L.; Fodor, T.; Liaudet, L.; Pacher, P. Poly(adp-ribose) polymerases as modulators of mitochondrial activity. Trends Endocrinol. Metab. TEM 2015, 26, 75-83. [CrossRef]

32. Shimizu, I.; Yoshida, Y.; Suda, M.; Minamino, T. DNA damage response and metabolic disease. Cell Metab. 2014, 20, 967-977. [CrossRef]

33. Bai, P.; Canto, C.; Oudart, H.; Brunyanszki, A.; Cen, Y.; Thomas, C.; Yamamoto, H.; Huber, A.; Kiss, B.; Houtkooper, R.H.; et al. Parp-1 inhibition increases mitochondrial metabolism through sirt1 activation. Cell Metab 2011, 13, 461-468. [CrossRef] [PubMed]

34. Bai, P.; Canto, C.; Brunyanszki, A.; Huber, A.; Szanto, M.; Cen, Y.; Yamamoto, H.; Houten, S.M.; Kiss, B.; Oudart, H.; et al. Parp-2 regulates sirt1 expression and whole-body energy expenditure. Cell Metab. 2011, 13, 450-460. [CrossRef] [PubMed]

35. Mohamed, J.S.; Hajira, A.; Pardo, P.S.; Boriek, A.M. Microrna-149 inhibits parp-2 and promotes mitochondrial biogenesis via sirt-1/pgc-1alpha network in skeletal muscle. Diabetes 2014, 63, 1546-1559. [CrossRef] [PubMed] 
36. Cerutti, R.; Pirinen, E.; Lamperti, C.; Marchet, S.; Sauve, A.A.; Li, W.; Leoni, V.; Schon, E.A.; Dantzer, F.; Auwerx, J.; et al. Nad(+)-dependent activation of sirt1 corrects the phenotype in a mouse model of mitochondrial disease. Cell Metab. 2014, 19, 1042-1049. [CrossRef]

37. Pirinen, E.; Canto, C.; Jo, Y.S.; Morato, L.; Zhang, H.; Menzies, K.J.; Williams, E.G.; Mouchiroud, L.; Moullan, N.; Hagberg, C.; et al. Pharmacological inhibition of poly(adp-ribose) polymerases improves fitness and mitochondrial function in skeletal muscle. Cell Metab. 2014, 19, 1034-1041. [CrossRef]

38. Kam, T.-I.; Mao, X.; Park, H.; Chou, S.-C.; Karuppagounder, S.S.; Umanah, G.E.; Yun, S.P.; Brahmachari, S.; Panicker, N.; Chen, R.; et al. Poly(adp-ribose) drives pathologic $\alpha$-synuclein neurodegeneration in parkinson's disease. Science 2018, 362, eaat8407. [CrossRef]

39. Litton, J.K.; Rugo, H.S.; Ettl, J.; Hurvitz, S.A.; Gonçalves, A.; Lee, K.-H.; Fehrenbacher, L.; Yerushalmi, R.; Mina, L.A.; Martin, M.; et al. Talazoparib in patients with advanced breast cancer and a germline brca mutation. New Engl. J. Med. 2018, 379, 753-763. [CrossRef]

40. Mateo, J.; Carreira, S.; Sandhu, S.; Miranda, S.; Mossop, H.; Perez-Lopez, R.; Nava Rodrigues, D.; Robinson, D.; Omlin, A.; Tunariu, N.; et al. DNA-repair defects and olaparib in metastatic prostate cancer. N. Engl. J. Med. 2015, 373, 1697-1708. [CrossRef]

41. O'Shaughnessy, J.; Osborne, C.; Pippen, J.E.; Yoffe, M.; Patt, D.; Rocha, C.; Koo, I.C.; Sherman, B.M.; Bradley, C. Iniparib plus chemotherapy in metastatic triple-negative breast cancer. New Engl. J. Med. 2011, 364, $205-214$. [CrossRef]

42. Wagner, L.M. Profile of veliparib and its potential in the treatment of solid tumors. Oncotargets Ther. 2015, 8, 1931-1939. [CrossRef] [PubMed]

43. Bhute, V.J.; Ma, Y.; Bao, X.; Palecek, S.P. The poly (adp-ribose) polymerase inhibitor veliparib and radiation cause significant cell line dependent metabolic changes in breast cancer cells. Sci. Rep. 2016, 6, 36061. [CrossRef] [PubMed]

44. Engert, F.; Schneider, C.; Weibeta, L.M.; Probst, M.; Fulda, S. Parp inhibitors sensitize ewing sarcoma cells to temozolomide-induced apoptosis via the mitochondrial pathway. Mol. Cancer Ther. 2015, 14, 2818-2830. [CrossRef] [PubMed]

45. Jugé, R.; Breugnot, J.; Da Silva, C.; Bordes, S.; Closs, B.; Aouacheria, A. Quantification and characterization of uvb-induced mitochondrial fragmentation in normal primary human keratinocytes. Sci. Rep. 2016, 6, 35065. [CrossRef] [PubMed]

46. Zanchetta, L.M.; Garcia, A.; Lyng, F.; Walsh, J.; Murphy, J.E. Mitophagy and mitochondrial morphology in human melanoma-derived cells post exposure to simulated sunlight. Int. J. Radiat. Biol. 2011, 87, 506-517. [CrossRef]

47. Paz, M.L.; Gonzalez Maglio, D.H.; Weill, F.S.; Bustamante, J.; Leoni, J. Mitochondrial dysfunction and cellular stress progression after ultraviolet $\mathrm{b}$ irradiation in human keratinocytes. Photodermatol. Photoimmunol. Photomed. 2008, 24, 115-122. [CrossRef]

48. Denning, M.F.; Wang, Y.; Tibudan, S.; Alkan, S.; Nickoloff, B.J.; Qin, J.Z. Caspase activation and disruption of mitochondrial membrane potential during uv radiation-induced apoptosis of human keratinocytes requires activation of protein kinase c. Cell Death Differ. 2002, 9, 40-52. [CrossRef]

49. Jing, L.; He, M.-T.; Chang, Y.; Mehta, S.L.; He, Q.-P.; Zhang, J.-Z.; Li, P.A. Coenzyme q10 protects astrocytes from ros-induced damage through inhibition of mitochondria-mediated cell death pathway. Int. J. Biol. Sci. 2015, 11, 59-66. [CrossRef]

50. Tondera, D.; Grandemange, S.; Jourdain, A.; Karbowski, M.; Mattenberger, Y.; Herzig, S.; Da Cruz, S.; Clerc, P.; Raschke, I.; Merkwirth, C.; et al. Slp-2 is required for stress-induced mitochondrial hyperfusion. EMBO J. 2009, 28, 1589-1600. [CrossRef]

51. Szanto, M.; Rutkai, I.; Hegedus, C.; Czikora, A.; Rozsahegyi, M.; Kiss, B.; Virag, L.; Gergely, P.; Toth, A.; Bai, P. Poly(adp-ribose) polymerase-2 depletion reduces doxorubicin-induced damage through sirt1 induction. Cardiovasc. Res. 2011, 92, 430-438. [CrossRef]

52. Shieh, W.M.; Ame, J.C.; Wilson, M.V.; Wang, Z.Q.; Koh, D.W.; Jacobson, M.K.; Jacobson, E.L. Poly(adp-ribose) polymerase null mouse cells synthesize adp-ribose polymers. J. Biol. Chem. 1998, 273, 30069-30072. [CrossRef]

53. Zarkovic, G.; Belousova, E.A.; Talhaoui, I.; Saint-Pierre, C.; Kutuzov, M.M.; Matkarimov, B.T.; Biard, D.; Gasparutto, D.; Lavrik, O.I.; Ishchenko, A.A. Characterization of DNA adp-ribosyltransferase activities of parp2 and parp3: New insights into DNA adp-ribosylation. Nucleic Acids Res. 2018, 46, 2417-2431. [CrossRef] 
54. King, B.S.; Cooper, K.L.; Liu, K.J.; Hudson, L.G. Poly(adp-ribose) contributes to an association between poly(adp-ribose) polymerase- 1 and xeroderma pigmentosum complementation group a in nucleotide excision repair. J. Biol. Chem. 2012, 287, 39824-39833. [CrossRef] [PubMed]

55. Dixit, M.; Kumar, A. Chapter 4-In vitro gene genotoxicity test methods. In In Vitro Toxicology; Dhawan, A., Kwon, S., Eds.; Academic Press: Cambridge, MA, USA, 2018; pp. 67-89.

56. Johnson, G. Mammalian cell hprt gene mutation assay: Test methods. In Genetic Toxicology; Springer: New York, NY, USA, 2012; Volume 817, pp. 55-67.

57. Hsie, A.W.; Couch, D.B.; O’Neill, J.P. Utilization of a Quantitative Mammalian Cell Mutation System, Cho/Hgprt, in Experimental Mutagenesis and Genetic Toxicology. Available online: https://www.osti.gov/ biblio/7278027 (accessed on 13 December 2019).

58. Hu, T.; Miller, C.M.; Ridder, G.M.; Aardema, M.J. Characterization of p53 in chinese hamster cell lines cho-k1, cho-wbl, and chl: Implications for genotoxicity testing. Mutat. Res. 1999, 426, 51-62. [CrossRef]

59. Tzang, B.S.; Lai, Y.C.; Hsu, M.; Chang, H.W.; Chang, C.C.; Huang, P.C.; Liu, Y.C. Function and sequence analyses of tumor suppressor gene p53 of cho.K1 cells. DNA Cell Biol. 1999, 18, 315-321. [CrossRef] [PubMed]

60. Lehman, T.A.; Modali, R.; Boukamp, P.; Stanek, J.; Bennett, W.P.; Welsh, J.A.; Metcalf, R.A.; Stampfer, M.R.; Fusenig, N.; Rogan, E.M.; et al. P53 mutations in human immortalized epithelial cell lines. Carcinogenesis 1993, 14, 833-839. [CrossRef] [PubMed]

61. Vyas, S.; Zaganjor, E.; Haigis, M.C. Mitochondria and cancer. Cell 2016, 166, 555-566. [CrossRef] [PubMed]

62. Onishi, Y.; Ueha, T.; Kawamoto, T.; Hara, H.; Toda, M.; Harada, R.; Minoda, M.; Kurosaka, M.; Akisue, T. Regulation of mitochondrial proliferation by pgc- $1 \alpha$ induces cellular apoptosis in musculoskeletal malignancies. Sci. Rep. 2014, 4, 3916. [CrossRef] [PubMed]

63. Saleem, A.; Adhihetty, P.J.; Hood, D.A. Role of p53 in mitochondrial biogenesis and apoptosis in skeletal muscle. Physiol. Genom. 2009, 37, 58-66. [CrossRef] [PubMed]

64. Dam, A. The Effect of Mitochondrial Biogenesis on Apoptotic Susceptibility in 16 Myoblasts. Master's Thesis, University of Waterloo, Waterloo, ON, Canada, 2010.

65. Gong, B.; Chen, Q.; Almasan, A. Ionizing radiation stimulates mitochondrial gene expression and activity. Radiat. Res. 1998, 150, 505-512. [CrossRef]

66. Yu, J.; Wang, Q.; Chen, N.; Sun, Y.; Wang, X.; Wu, L.; Chen, S.; Yuan, H.; Xu, A.; Wang, J. Mitochondrial transcription factor a regulated ionizing radiation-induced mitochondrial biogenesis in human lung adenocarcinoma a549 cells. J. Radiat. Res. 2013, 54, 998-1004. [CrossRef] [PubMed]

67. Eliopoulos, A.G.; Havaki, S.; Gorgoulis, V.G. DNA damage response and autophagy: A meaningful partnership. Front. Genet. 2016, 7, 204. [CrossRef] [PubMed]

68. Qiang, L.; Zhao, B.; Shah, P.; Sample, A.; Yang, S.; He, Y.Y. Autophagy positively regulates DNA damage recognition by nucleotide excision repair. Autophagy 2016, 12, 357-368. [CrossRef] [PubMed]

69. Wang, H.-T.; Lin, J.-H.; Yang, C.-H.; Haung, C.-H.; Weng, C.-W.; Maan-Yuh Lin, A.; Lo, Y.-L.; Chen, W.-S.; Tang, M.-S. Acrolein induces mtdna damages, mitochondrial fission and mitophagy in human lung cells. Oncotarget 2017, 8, 70406-70421. [CrossRef] [PubMed]

70. Rodríguez-Vargas, J.M.; Rodríguez, M.I.; Majuelos-Melguizo, J.; García-Diaz, Á.; González-Flores, A.; López-Rivas, A.; Virág, L.; Illuzzi, G.; Schreiber, V.; Dantzer, F.; et al. Autophagy requires poly(adp-ribosyl)ation-dependent ampk nuclear export. Cell Death Differ. 2016, 23, 2007. [CrossRef] [PubMed]

71. Rodríguez-Vargas, J.M.; Ruiz-Magaña, M.J.; Ruiz-Ruiz, C.; Majuelos-Melguizo, J.; Peralta-Leal, A.; Rodríguez, M.I.; Muñoz-Gámez, J.A.; de Almodóvar, M.R.; Siles, E.; Rivas, A.L.; et al. Ros-induced DNA damage and parp-1 are required for optimal induction of starvation-induced autophagy. Cell Res. 2012, 22, 1181-1198. [CrossRef] [PubMed]

72. Muñoz-Gámez, J.A.; Rodríguez-Vargas, J.M.; Quiles-Pérez, R.; Aguilar-Quesada, R.; Martín-Oliva, D.; de Murcia, G.; de Murcia, J.M.; Almendros, A.; de Almodóvar, M.R.; Oliver, F.J. Parp-1 is involved in autophagy induced by DNA damage. Autophagy 2009, 5, 61-74. [CrossRef] [PubMed]

73. Wyrsch, P.; Blenn, C.; Bader, J.; Althaus, F.R. Cell death and autophagy under oxidative stress: Roles of poly(adp-ribose) polymerases and Ca2+. Mol. Cell. Biol. 2012, 32, 3541-3553. [CrossRef] [PubMed]

74. Rajawat, J.; Shukla, N.; Mishra, D.P. Therapeutic targeting of poly(adp-ribose) polymerase-1 (parp1) in cancer: Current developments, therapeutic strategies, and future opportunities. Med. Res. Rev. 2017, 37, 1461-1491. [CrossRef] 
75. Arun, B.; Akar, U.; Gutierrez-Barrera, A.M.; Hortobagyi, G.N.; Ozpolat, B. The parp inhibitor azd2281 (olaparib) induces autophagy/mitophagy in brca1 and brca2 mutant breast cancer cells. Int. J. Oncol. 2015, 47, 262-268. [CrossRef]

76. Rambold, A.S.; Kostelecky, B.; Elia, N.; Lippincott-Schwartz, J. Tubular network formation protects mitochondria from autophagosomal degradation during nutrient starvation. Proc. Natl. Acad. Sci. USA 2011, 108, 10190-10195. [CrossRef] [PubMed]

77. Biel, T.G.; Rao, V.A. Mitochondrial dysfunction activates lysosomal-dependent mitophagy selectively in cancer cells. Oncotarget 2018, 9, 995-1011. [CrossRef] [PubMed]

78. Eyschen, J.; Vitoux, B.; Marraud, M.; Cung, M.T.; Branlant, G. Engineered glycolytic glyceraldehyde-3-phosphate dehydrogenase binds the anti conformation of nad + nicotinamide but does not experience a-specific hydride transfer. Arch. Biochem. Biophys. 1999, 364, 219-227. [CrossRef] [PubMed]

79. Santidrian, A.F.; Matsuno-Yagi, A.; Ritland, M.; Seo, B.B.; LeBoeuf, S.E.; Gay, L.J.; Yagi, T.; Felding-Habermann, B. Mitochondrial complex i activity and nad+/nadh balance regulate breast cancer progression. J. Clin. Investig. 2013, 123, 1068-1081. [CrossRef] [PubMed]

80. Imai, S.-I.; Guarente, L. It takes two to tango: Nad+ and sirtuins in aging/longevity control. NPJ Aging Mech. Dis. 2016, 2, 16017. [CrossRef]

81. Morris, B.J. Seven sirtuins for seven deadly diseases of aging. Free Radic. Biol. Med. 2013, 56, $133-171$. [CrossRef]

82. Canto, C.; Sauve, A.A.; Bai, P. Crosstalk between poly(adp-ribose) polymerase and sirtuin enzymes. Mol. Asp. Med. 2013, 34, 1168-1201. [CrossRef]

83. Luna, A.; Aladjem, M.I.; Kohn, K.W. Sirt1/parp1 crosstalk: Connecting DNA damage and metabolism. Genome Integr. 2013, 4, 6. [CrossRef]

84. Ming, M.; Soltani, K.; Shea, C.R.; Li, X.; He, Y.Y. Dual role of sirt1 in uvb-induced skin tumorigenesis. Oncogene 2015, 34, 357-363. [CrossRef]

85. Cao, C.; Lu, S.; Kivlin, R.; Wallin, B.; Card, E.; Bagdasarian, A.; Tamakloe, T.; Wang, W.J.; Song, X.; Chu, W.M.; et al. Sirt1 confers protection against uvb- and h2o2-induced cell death via modulation of p53 and jnk in cultured skin keratinocytes. J. Cell. Mol. Med. 2009, 13, 3632-3643. [CrossRef]

86. Benavente, C.A.; Schnell, S.A.; Jacobson, E.L. Effects of niacin restriction on sirtuin and parp responses to photodamage in human skin. PLoS ONE 2012, 7, e42276. [CrossRef] [PubMed]

87. Scher, M.B.; Vaquero, A.; Reinberg, D. Sirt3 is a nuclear nad+-dependent histone deacetylase that translocates to the mitochondria upon cellular stress. Genes Dev. 2007, 21, 920-928. [CrossRef] [PubMed]

88. Garcia-Peterson, L.M.; Wilking-Busch, M.J.; Ndiaye, M.A.; Philippe, C.G.A.; Setaluri, V.; Ahmad, N. Sirtuins in skin and skin cancers. Ski. Pharmacol. Physiol. 2017, 30, 216-224. [CrossRef] [PubMed]

89. Robu, M.; Shah, R.G.; Purohit, N.K.; Zhou, P.; Naegeli, H.; Shah, G.M. Poly(adp-ribose) polymerase 1 escorts xpc to uv-induced DNA lesions during nucleotide excision repair. Proc. Natl. Acad. Sci. USA 2017, 114, E6847-e6856. [CrossRef] [PubMed]

90. Robu, M.; Shah, R.G.; Petitclerc, N.; Brind'Amour, J.; Kandan-Kulangara, F.; Shah, G.M. Role of poly(adp-ribose) polymerase-1 in the removal of uv-induced DNA lesions by nucleotide excision repair. Proc. Natl. Acad. Sci. USA 2013, 110, 1658-1663. [CrossRef] [PubMed]

91. Pines, A.; Vrouwe, M.G.; Marteijn, J.A.; Typas, D.; Luijsterburg, M.S.; Cansoy, M.; Hensbergen, P.; Deelder, A.; de Groot, A.; Matsumoto, S.; et al. Parp1 promotes nucleotide excision repair through ddb2 stabilization and recruitment of alc1. J. Cell Biol. 2012, 199, 235-249. [CrossRef] [PubMed]

92. Ciccarone, F.; Zampieri, M.; Caiafa, P. Parp1 orchestrates epigenetic events setting up chromatin domains. Semin. Cell Dev. Biol. 2017, 63, 123-134. [CrossRef] [PubMed]

93. Murai, J.; Zhang, Y.; Morris, J.; Ji, J.; Takeda, S.; Doroshow, J.H.; Pommier, Y. Rationale for poly(adp-ribose) polymerase (parp) inhibitors in combination therapy with camptothecins or temozolomide based on parp trapping versus catalytic inhibition. J. Pharmacol. Exp. Ther. 2014, 349, 408-416. [CrossRef] [PubMed]

94. Prasad, C.B.; Prasad, S.B.; Yadav, S.S.; Pandey, L.K.; Singh, S.; Pradhan, S.; Narayan, G. Olaparib modulates DNA repair efficiency, sensitizes cervical cancer cells to cisplatin and exhibits anti-metastatic property. Sci. Rep. 2017, 7, 12876. [CrossRef]

95. Jelinic, P.; Levine, D.A. New insights into parp inhibitors' effect on cell cycle and homology-directed DNA damage repair. Mol. Cancer Ther. 2014, 13, 1645-1654. [CrossRef] [PubMed] 
96. Murai, J.; Huang, S.Y.; Das, B.B.; Renaud, A.; Zhang, Y.; Doroshow, J.H.; Ji, J.; Takeda, S.; Pommier, Y. Trapping of parp1 and parp2 by clinical parp inhibitors. Cancer Res. 2012, 72, 5588-5599. [CrossRef] [PubMed]

97. Helleday, T. The underlying mechanism for the parp and brca synthetic lethality: Clearing up the misunderstandings. Mol. Oncol. 2011, 5, 387-393. [CrossRef]

98. Horton, J.K.; Wilson, S.H. Strategic combination of DNA-damaging agent and parp inhibitor results in enhanced cytotoxicity. Front. Oncol. 2013, 3, 257. [CrossRef]

99. Muvarak, N.E.; Chowdhury, K.; Xia, L.; Robert, C.; Choi, E.Y.; Cai, Y.; Bellani, M.; Zou, Y.; Singh, Z.N.; Duong, V.H.; et al. Enhancing the cytotoxic effects of parp inhibitors with DNA demethylating agents-A potential therapy for cancer. Cancer Cell 2016, 30, 637-650. [CrossRef] [PubMed]

100. Plummer, R.; Dua, D.; Cresti, N.; Suder, A.; Drew, Y.; Prathapan, V.; Stephens, P.; Thornton, J.K.; de las Heras, B.; Ink, B.; et al. Phase 1 study of the parp inhibitor e7449 as a single agent in patients with advanced solid tumors or b-cell lymphoma. J. Clin. Oncol. 2014, 32, e19531. [CrossRef]

101. O'Cearbhaill, R.E. Using parp inhibitors in advanced ovarian cancer. Oncology 2018, 32, 339-343.

102. Alano, C.C.; Garnier, P.; Ying, W.; Higashi, Y.; Kauppinen, T.M.; Swanson, R.A. Nad+ depletion is necessary and sufficient for poly(adp-ribose) polymerase-1-mediated neuronal death. J. Neurosci. Off. J. Soc. Neurosci. 2010, 30, 2967-2978. [CrossRef]

103. Eguchi, Y.; Shimizu, S.; Tsujimoto, Y. Intracellular atp levels determine cell death fate by apoptosis or necrosis. Cancer Res. 1997, 57, 1835-1840.

104. Zamaraeva, M.V.; Sabirov, R.Z.; Maeno, E.; Ando-Akatsuka, Y.; Bessonova, S.V.; Okada, Y. Cells die with increased cytosolic atp during apoptosis: A bioluminescence study with intracellular luciferase. Cell Death Differ. 2005, 12, 1390-1397. [CrossRef]

105. Fu, D.; Lippincott-Schwartz, J.; Arias, I.M. Increased mitochondrial fusion and autophagy help isolated hepatocytes repolarize in collagen sandwich cultures. Autophagy 2013, 9, 2154-2155. [CrossRef]

106. Thomas, H.E.; Zhang, Y.; Stefely, J.A.; Veiga, S.R.; Thomas, G.; Kozma, S.C.; Mercer, C.A. Mitochondrial complex i activity is required for maximal autophagy. Cell Rep. 2018, 24, 2404-2417.e2408. [CrossRef] [PubMed]

107. Montecucco, A.; Zanetta, F.; Biamonti, G. Molecular mechanisms of etoposide. EXCLI J. 2015, 14, 95-108.

108. Chatterjee, N.; Walker, G.C. Mechanisms of DNA damage, repair, and mutagenesis. Environ. Mol. Mutagenesis 2017, 58, 235-263. [CrossRef] [PubMed]

109. Ray, A.; Milum, K.; Battu, A.; Wani, G.; Wani, A.A. Ner initiation factors, ddb2 and xpc, regulate uv radiation response by recruiting atr and atm kinases to DNA damage sites. DNA Repair 2013, 12, 273-283. [CrossRef]

110. Sun, Y.; Connors, K.E.; Yang, D.Q. Aicar induces phosphorylation of ampk in an atm-dependent, lkb1-independent manner. Mol. Cell. Biochem. 2007, 306, 239-245. [CrossRef] [PubMed]

111. Lavin, M.F.; Kozlov, S. Atm activation and DNA damage response. Cell Cycle 2007, 6, 931-942. [CrossRef]

112. Viniegra, J.G.; Martinez, N.; Modirassari, P.; Hernandez Losa, J.; Parada Cobo, C.; Sanchez-Arevalo Lobo, V.J.; Aceves Luquero, C.I.; Alvarez-Vallina, L.; Ramon y Cajal, S.; Rojas, J.M.; et al. Full activation of pkb/akt in response to insulin or ionizing radiation is mediated through atm. J. Biol. Chem. 2005, 280, 4029-4036. [CrossRef] [PubMed]

113. Khalil, H.; Tummala, H.; Zhelev, N. ATM in focus: A damage sensor and cancer target. Biodiscovery $2012,5$. [CrossRef]

114. Jones, R.G.; Plas, D.R.; Kubek, S.; Buzzai, M.; Mu, J.; Xu, Y.; Birnbaum, M.J.; Thompson, C.B. Amp-activated protein kinase induces a p53-dependent metabolic checkpoint. Mol. Cell 2005, 18, 283-293. [CrossRef] [PubMed]

115. Zhang, J.; Wang, Y.; Liu, X.; Dagda, R.K.; Zhang, Y. How ampk and pka interplay to regulate mitochondrial function and survival in models of ischemia and diabetes. Oxidative Med. Cell. Longev. 2017, 2017, 12. [CrossRef]

116. Wang, D.B.; Kinoshita, C.; Kinoshita, Y.; Morrison, R.S. P53 and mitochondrial function in neurons. Biochim. Biophys. Acta 2014, 1842, 1186-1197. [CrossRef] [PubMed]

117. Parra, V.; Verdejo, H.E.; Iglewski, M.; Del Campo, A.; Troncoso, R.; Jones, D.; Zhu, Y.; Kuzmicic, J.; Pennanen, C.; Lopez-Crisosto, C.; et al. Insulin stimulates mitochondrial fusion and function in cardiomyocytes via the akt-mtor-nfkappab-opa-1 signaling pathway. Diabetes 2014, 63, 75-88. [CrossRef] [PubMed] 
118. Morita, M.; Prudent, J.; Basu, K.; Goyon, V.; Katsumura, S.; Hulea, L.; Pearl, D.; Siddiqui, N.; Strack, S.; McGuirk, S.; et al. Mtor controls mitochondrial dynamics and cell survival via mtfp1. Mol. Cell 2017, 67, 922-935.e925. [CrossRef] [PubMed]

119. Boukamp, P.; Petrussevska, R.T.; Breitkreutz, D.; Hornung, J.; Markham, A.; Fusenig, N.E. Normal keratinization in a spontaneously immortalized aneuploid human keratinocyte cell line. J. Cell Biol. 1988, 106, 761-771. [CrossRef]

120. Boros, G.; Miko, E.; Muramatsu, H.; Weissman, D.; Emri, E.; Rozsa, D.; Nagy, G.; Juhasz, A.; Juhasz, I.; van der Horst, G.; et al. Transfection of pseudouridine-modified mrna encoding cpd-photolyase leads to repair of DNA damage in human keratinocytes: A new approach with future therapeutic potential. J. Photochem. Photobiol. B Biol. 2013, 129, 93-99. [CrossRef]

121. Chomczynski, P.; Sacchi, N. Single-step method of rna isolation by acid guanidinium thiocyanate-phenolchloroform extraction. Anal. Biochem. 1987, 162, 156-159. [CrossRef]

122. Balogh, A.; Paragh, G., Jr.; Juhasz, A.; Kobling, T.; Torocsik, D.; Miko, E.; Varga, V.; Emri, G.; Horkay, I.; Scholtz, B.; et al. Reference genes for quantitative real time pcr in uvb irradiated keratinocytes. J. Photochem. Photobiol. B Biol. 2008, 93, 133-139. [CrossRef]

123. Rueden, C.T.; Schindelin, J.; Hiner, M.C.; DeZonia, B.E.; Walter, A.E.; Arena, E.T.; Eliceiri, K.W. Imagej2: Imagej for the next generation of scientific image data. BMC Bioinform. 2017, 18, 529. [CrossRef]

124. Merrill, R.A.; Flippo, K.H.; Strack, S. Measuring mitochondrial shape with imagej. In Techniques to Investigate Mitochondrial Function in Neurons; Strack, S., Usachev, Y.M., Eds.; Springer: New York, NY, USA, 2017; pp. 31-48.

(C) 2019 by the authors. Licensee MDPI, Basel, Switzerland. This article is an open access article distributed under the terms and conditions of the Creative Commons Attribution (CC BY) license (http://creativecommons.org/licenses/by/4.0/). 